ARTICLE

\title{
Atypical natural killer T-cell receptor recognition of CD1d-lipid antigens
}

Jérôme Le Nours ${ }^{1,2, \star}$, T. Praveena ${ }^{1, \star}$, Daniel G. Pellicci ${ }^{3,4, \star}$, Nicholas A. Gherardin ${ }^{3,5}$, Fiona J. Ross ${ }^{3,4}$, Ricky T. Lim³, Gurdyal S. Besra6 ${ }^{6}$, Santosh Keshipeddy ${ }^{7}$, Stewart K. Richardson7 , Amy R. Howell7, Stephanie Gras ${ }^{1,2}$, Dale I. Godfrey ${ }^{3,4, \star \star}$, Jamie Rossjohn ${ }^{1,2,8, \star \star} \&$ Adam P. Uldrich $^{3,4, \star \star}$

Crucial to Natural Killer T (NKT) cell function is the interaction between their T-cell receptor (TCR) and CD1d-antigen complex. However, the diversity of the NKT cell repertoire and the ensuing interactions with CD1d-antigen remain unclear. We describe an atypical population of CD1d- $\alpha$-galactosylceramide ( $\alpha$-GalCer)-reactive human NKT cells that differ markedly from the prototypical TRAV10-TRAJ18-TRBV25-1 ${ }^{+}$type I NKT cell repertoire. These cells express a range of TCR $\alpha$ - and $\beta$-chains that show differential recognition of glycolipid antigens. Two atypical NKT TCRs (TRAV21-TRAJ8-TRBV7-8 and TRAV12-3-TRAJ27-TRBV6-5) bind orthogonally over the $A^{\prime}$-pocket of CD1d, adopting distinct docking modes that contrast with the docking mode of all type I NKT TCR-CD1d-antigen complexes. Moreover, the interactions with $\alpha$-GalCer differ between the type I and these atypical NKT TCRs. Accordingly, diverse NKT TCR repertoire usage manifests in varied docking strategies and specificities towards CD1d- $\alpha$-GalCer and related antigens, thus providing far greater scope for diverse glycolipid antigen recognition.

\footnotetext{
${ }^{1}$ Infection and Immunity Program \& Department of Biochemistry and Molecular Biology, Biomedicine Discovery Institute, Monash University, Clayton, Victoria 3800, Australia. ${ }^{2}$ Australian Research Council Centre of Excellence for Advanced Molecular Imaging, Monash University, Clayton, Victoria 3800, Australia. ${ }^{3}$ Department of Microbiology and Immunology, Peter Doherty Institute for Infection and Immunity, University of Melbourne, Melbourne, Victoria 3000, Australia. ${ }^{4}$ Australian Research Council Centre of Excellence for Advanced Molecular Imaging, University of Melbourne, Melbourne, Victoria 3000, Australia. ${ }^{5}$ Cancer Immunology Research Program, Research Division, Peter MacCallum Cancer Centre, East Melbourne, Victoria 3002, Australia. ${ }^{6}$ School of Biosciences, University of Birmingham, Edgbaston, Birmingham B15 2TT, UK. ${ }^{7}$ Department of Chemistry, University of Connecticut, Storrs, Connecticut 06269-3060, USA. ${ }^{8}$ Institute of Infection and Immunity, Cardiff University, School of Medicine, Heath Park, Cardiff CF14 4XN, UK. ${ }^{*}$ These authors contributed equally to this work. ${ }^{\star \star}$ These authors jointly supervised this work. Correspondence and requests for materials should be addressed to D.I.G. (email: godfrey@unimelb.edu.au) or to J.R. (email: Jamie.rossjohn@monash.edu) or to A.P.U. (email: auldrich@unimelb.edu.au).
} 
$\beta \mathrm{T}$ cells can be activated by peptides, metabolites and lipids when bound to their requisite antigen $(\mathrm{Ag})$-presenting molecules ${ }^{1-3}$. The CD1 family of MHC-class I-like molecules present an array of endogenous and foreign lipids Ags that are recognized by specialized T-cell populations ${ }^{4,5}$. For example, NKT cells are activated by lipidbased Ags presented by CD1d ${ }^{6}$. Based on ligand specificity and $\alpha \beta$ TCR composition, NKT cells are broadly sub-divided into two populations, type I and II. $\alpha$-Galactosylceramide ( $\alpha$-GalCer) is the prototypical Ag for type I NKT cells, which express an invariant TCR $\alpha$-chain (TRAV10 ${ }^{+}$TRAJ18 ${ }^{+}(\mathrm{V} \alpha 24-J \alpha 18)$ in humans and the orthologous TRAV11 ${ }^{+} \mathrm{TRAJ}_{18}{ }^{+}(\mathrm{V} \alpha 14-\mathrm{J} \alpha 18)$ in mice $)^{6-8}$. While type II NKT cells display a diverse TCR repertoire, and while their Ag-specificity remains unclear, they are nevertheless characterized as being non-reactive towards $\alpha$-GalCer ${ }^{6,9}$. The apparent functional divergence between type I and type II NKT cells arises, in part, from the interaction between the NKT TCR and CD1d-Ag.

Despite the prototypical type I NKT TCR gene usage, variations within the $\mathrm{CD} 1 \mathrm{~d}-\alpha-\mathrm{GalCer}$ reactive repertoire exist that subsequently impact on ligand specificity and functional outcome. For example, while human type I NKT cells typically use TRBV25-1 (V $\beta 11)$-encoded TCR $\beta$-chains, mouse type I NKT cells can utilize TRBV13 (V $\beta 8)$, TRBV29 (V $\beta 7)$ and TRBV1 (V $\beta 2)$ TCR $\beta$-chains, with the variations in the TRBV repertoire impacting on the range of ligands a given NKT TCR can interact with ${ }^{10-16}$. Similarly, both mouse and human NKT cells can utilize alternative TCR $\alpha$-chains that retains $\alpha$-GalCer reactivity ${ }^{17-21}$. For example, TRAV $10^{-}$TRAJ $18^{+}$TRBV25-1 $^{+}$NKT cells comprise up to $15 \%$ of human CD1d- $\alpha$-GalCer reactive NKT cells $^{17}$. Despite their comparable reactivity to $\alpha$-GalCer and their identical TRAJ18 usage, these cells appear to exhibit a lower affinity towards $\alpha$-glucosylceramide ( $\alpha$-GlcCer) compared with the TRAV $10^{+}$TRAJ $18^{+}$type I NKT cells ${ }^{17}$. In contrast, mouse TRAV13- $3^{+} \mathrm{TRAJ}_{50}{ }^{+} \mathrm{TRBV} 3^{+}\left(\mathrm{V} \alpha 10^{+} \mathrm{J} \alpha 50^{+} \mathrm{V} \beta 8^{+}\right) \mathrm{CD} 1 \mathrm{~d}-$ $\alpha$-GalCer reactive NKT cells exhibited a greater reactivity towards $\alpha$-GlcCer in comparison to $\alpha$-GalCer, and they were selectively reactive to a mycobacterial Ag $\alpha$-glucuronosyldiacylglycerol ${ }^{19}$. Moreover, a population of $\alpha$-GalCer-reactive TRDV1 ${ }^{+}\left(\mathrm{V} \delta 1^{+}\right)$ $\gamma \delta \mathrm{T}$ cells was identified recently, and these cells also exhibited a distinct lipid-Ag-binding profile, thereby highlighting the breadth of TCR usage that engenders CD1d- $\alpha$-GalCer recognition ${ }^{22}$. Therefore, if we are to fully understand the significance and therapeutic potential of CD1d-lipid Ag recognition in the immune system, it is vital to understand how variations within the NKT TCR repertoire impacts on CD1d-Ag recognition.

The crystal structures of a large panel of human and mouse type I NKT TCRs have been determined in complex with CD1d presenting a broad repertoire of chemically distinct lipids including synthetic ligands, self- and microbial ligands ${ }^{10-12,15,19,20,23-34}$. Universally, despite the NKT cell repertoire and antigenic variations, the resultant type I NKT $\alpha \beta T C R-C D 1 d-A g$ complexes exhibit a highly conserved docking strategy. Namely, the type I NKT TCR docks, in a parallel manner, over the $\mathrm{F}^{\prime}$-pocket of $\mathrm{CD} \mathrm{d}^{8}$. Here the semi-invariant type I NKT TCR $\alpha$-chain dominated the interaction, binding to CD1d and Ag, whereas the TCR $\beta$-chain ligated only to CD1d. Nevertheless, within this consensus footprint, altered contributions from the complementarity determining regions (CDRs) of the NKT TCR led to differing patterns of CD1d-Ag reactivity. For example, the CDR3 $\beta$ loop modulated the extent of CD1d autoreactivity and, hence, the functional response to lipid Ags, despite not contacting the Ag directly ${ }^{25,35}$. Moreover, the heightened reactivity of the TRAV13-3 ${ }^{+}$TRAJ50 ${ }^{+}$NKT cells towards $\alpha$-GlcCer was attributable to favourable interactions of the $\alpha$-GlcCer moiety with the TCR $\alpha$-chain ${ }^{19}$. While some type II NKT TCRs can dock differently on CD1d, these do not react with $\alpha$-GalCer and utilize entirely different TCR V genes ${ }^{36,37}$. Thus, the question of whether CD1d- $\alpha$-GalCer-reactive NKT $\alpha \beta T C R s$ can adopt alternative binding modes that may provide greater diversity in Ag recognition remains to be determined, and this represents an important issue in understanding the scope of lipid Ag recognition by NKT cells.

Here we describe a diverse population of CD1d- $\alpha$-GalCer reactive cells that we termed 'atypical NKT cells' because they lack the invariant TRAV10 ${ }^{+} \mathrm{TRAJ}_{18}{ }^{+} \alpha$-chain and the TRBV25-1 $\beta$-chain that are inherent to type I NKT cells. These atypical NKT cells exhibited differing specificities towards lipid Ags compared with that of type I NKT TCRs. Importantly, these atypical NKT cells could respond to glycolipid Ag presented by CD1d with diverse cytokine production, similar to type I NKT cells. Crystal structures of two of these atypical NKT TCRs in complex with CD1d- $\alpha$ GalCer showed that, in contrast to type I NKT cell TCRs that dock over the $\mathrm{F}^{\prime}$-pocket of CD1d- $\alpha$-GalCer, these atypical TCRs docked orthogonally over the $\mathrm{A}^{\prime}$-pocket of CD1d- $\alpha$-GalCer. Furthermore, the interactions with the lipid Ag were completely distinct from those observed with type I NKT TCRs engaging $\alpha$-GalCer-CD1d complexes. Thus, variations in the CD1d- $\alpha-$ GalCer-reactive NKT TCR repertoire can manifest in alternative docking strategies on CD1d and diverse reactivity towards CD1d-restricted lipids.

\section{Results}

A diverse human type I NKT cell repertoire. A defining characteristic of type I NKT cells is their reactivity towards the prototypical type I NKT cell Ag, $\alpha$-GalCer, presented by CD1d ${ }^{6}$. The human type I NKT cell repertoire is comprised of the invariant TRAV $10^{+}$TRAJ18 ${ }^{+}$TRBV25-1 ${ }^{+}$NKT cells. Given that a range of TCR $\beta$-chains can support CD1d- $\alpha$-GalCer recognition in mice ${ }^{8}$, we were interested in exploring whether a similar population of TRBV25-1 ${ }^{-}$NKT cells existed in humans. To establish this, we isolated and expanded CD1d- $\alpha$-GalCer reactive NKT cells from healthy human blood donors and performed analytical flow cytometry to identify non-canonical NKT cell TCR subsets, by staining with antibodies specific for TRAV10 and TRBV25-1, along with $\gamma \delta$ TCR and TRDV1 to exclude CD1d- $\alpha$-GalCer-reactive $\gamma \delta$ T-cells from the analysis ${ }^{22}$. Using this approach, we detected a clear population of TRBV25-1 ${ }^{-}$NKT cells, that, in most donors, did not react with 'endogenous' CD1d tetramers, thus implying these cells recognized $\alpha$-GalCer presented by CD1d (Fig. 1a). Consistent with earlier studies ${ }^{17,38}$, a population of TRAV10 ${ }^{-}$NKT cells was also detected, although interestingly, the proportion of the TRBV25-1 ${ }^{-}$and the TRAV10 ${ }^{-}$populations within each sample did not always coincide, suggesting that these two subsets were at least partially mutually exclusive. Costaining with CD4 and CD8 $\alpha$ co-receptors revealed a variable pattern of expression on the CD1d- $\alpha$-GalCer-restricted TRBV25-1 ${ }^{-}$cells compared with type I NKT cells (Fig. 1a,b). A more extensive phenotypic analysis of four donors with a detectable population of these cells indicated that while both TRBV25-1 ${ }^{+}$(type I) and TRBV25-1CD1d- $\alpha$-GalCer-reactive cells expressed NKG2D (three out of four donors each), there was very little or no expression of a panel of killer inhibitory receptors (including CD158A/B/F/ $\mathrm{G} / \mathrm{H}$ ) or CD56 (Supplementary Fig. 1). Furthermore, CD161 was clearly expressed on the TRBV25-1 ${ }^{-}$cells in two out of four donors, versus three out of four donors for type I NKT cells. Thus, while there appears to be significant heterogeneity in the phenotypic profiles of TRBV25-1 ${ }^{-}$cells between 
a

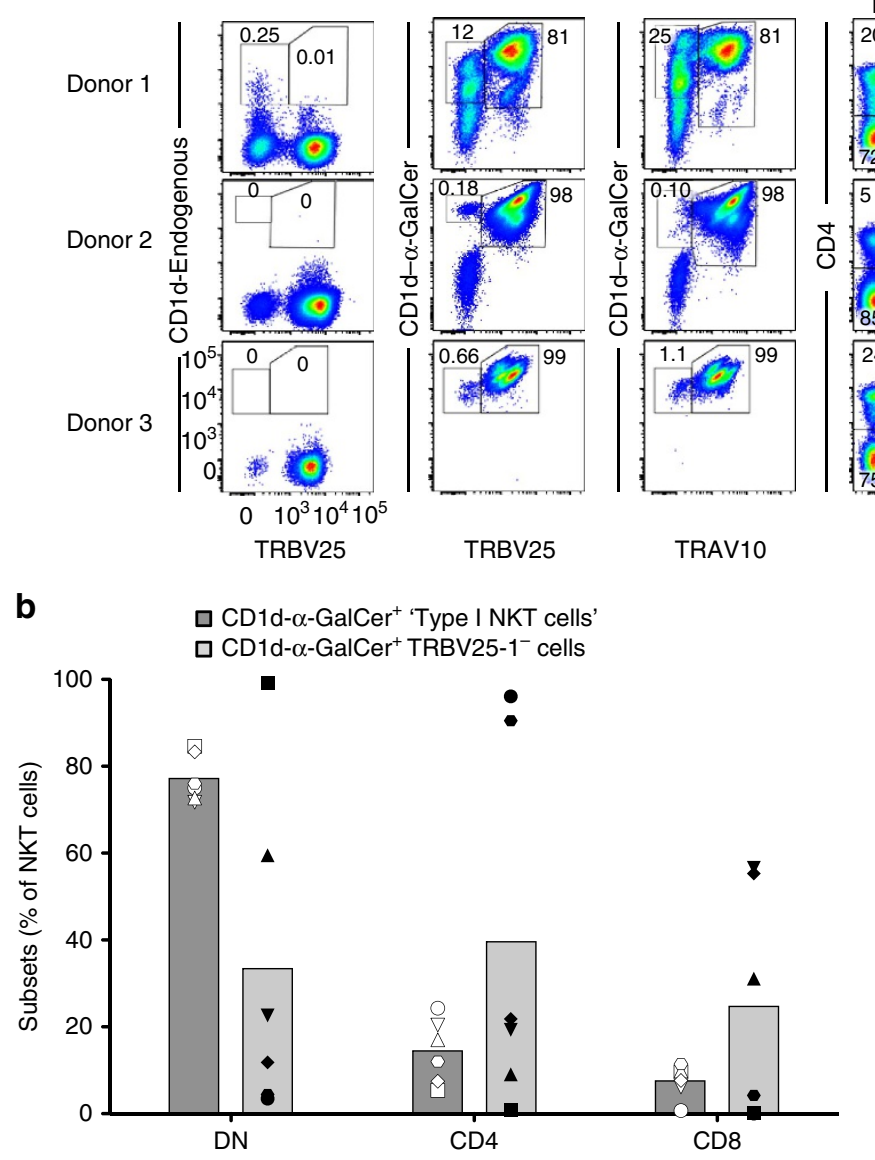

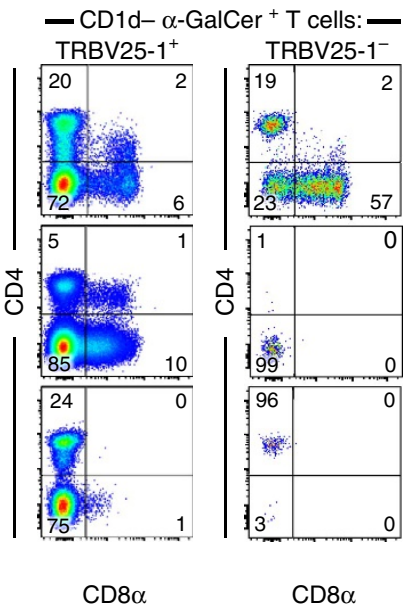

C

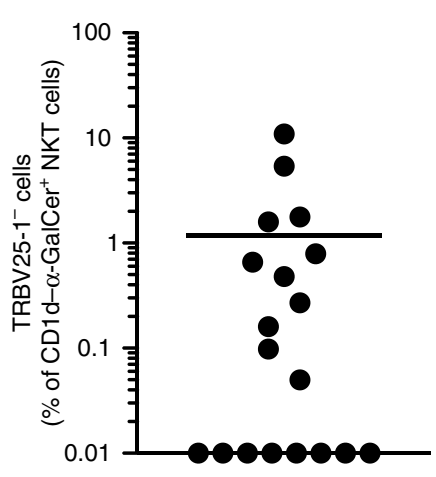

Figure 1 | Identification of CD1d- $\alpha$-GalCer reactive atypical NKT cells. (a) Flow cytometry of CD1d- $\alpha$-GalCer reactive cells enriched and expanded from PBMCs from three healthy human donors. TRDV1- $\gamma \delta \mathrm{TCR}^{-}$cells were analysed for the expression of TRBV25-1 versus CD1d-endogenous tetramer or CD1d- $\alpha$-GalCer tetramer (left-hand density plots). TRDV1 ${ }^{-} \gamma \delta$ TCR $^{-}$CD1d- $\alpha-G a l C e r$ tetramer ${ }^{+}$cells were analysed for the expression of TRAV10 (middle density plots). CD1d- $\alpha$-GalCer tetramer ${ }^{+}$TRBV25-1 ${ }^{+}$type I cells and CD1d- $\alpha-G a l C e r$ tetramer ${ }^{+}$TRBV25-1 ${ }^{-}$cells were analysed for the expression of CD4 and CD $8 \alpha$ (right-side density plots). (b) The mean percentage of double negative (DN), CD4 ${ }^{+}$and CD8 ${ }^{+}$cells among CD1d- $\alpha-G a l C e r$ tetramer ${ }^{+}$ TRBV25 + Type I cells (dark grey) and CD1d- $\alpha$-GalCer tetramer ${ }^{+}$TRBV25- cells (light grey). Each symbol represents cells from a different donor $(n=6)$. (c) The mean percentage of CD1d- $\alpha$-GalCer tetramer ${ }^{+}$TRBV25 ${ }^{-}$cells of total CD1d- $\alpha$-GalCer reactive NKT cells, from 19 individual donors. Donors that showed no clear population of atypical NKT cells were given an arbitrary value of $0.01 \%$.

donors, at least in some cases they resemble type I NKT cells. Analysis of additional donors confirmed that the $\gamma \delta \mathrm{TCR}^{-}$ TRBV25-1 ${ }^{-}$subset was clearly detectable in $11 / 19$ individuals, where they ranged from 0 to $10 \%$ of all CD1d$\alpha$-GalCer reactive (type I) NKT cells (Fig. 1c). Given that type I NKT cells generally represent $\sim 0.01-0.1 \%$ of peripheral blood lymphocytes, this indicates that these cells are normally quite rare, and in most cases, we could only readily detect them after in vitro enrichment/expansion of CD1d- $\alpha$-GalCer-reactive cells.

To determine the paired TCR $\alpha$ and $\beta$ chain usage of these cells, we performed single-cell TCR sequencing and compared gene usage with TRAV $10^{+}$TRBV25-1 ${ }^{+}$type I NKT cells sorted from the same donors. The sequencing results confirmed that there appeared to be two distinct subsets of non-canonical CD1d$\alpha$-GalCer-reactive T cells based on TCR gene usage. One of these exhibited a TRAV10-TRBV25-1 ${ }^{+}$phenotype, and was only identified within the TRAV10 ${ }^{-}$population, whereas the second was TRAV10 ${ }^{-}$TRBV25-1 ${ }^{-}$, and was present within both the TRAV10 ${ }^{-}$and TRBV25-1 ${ }^{-}$populations (Table 1 ). Interestingly, these data also revealed a close association between TRAJ18 and TRBV25-1 gene usage. For example, eight out of eight unique
TRBV25-1 $1^{+}$TCR sequences that lacked the TRAV10 TCR $\alpha$-chain still expressed TRAJ18. In contrast, only one out of fourteen unique TCR sequences that were TRBV25-1utilized TRAJ18 $(P<0.0001$; Fisher's exact test). Instead, this TRBV25-1 ${ }^{-}$population displayed a broad spectrum of TRAV and TRAJ gene usage (Table 1). Thus, from TRBV25-1 ${ }^{-}$cells, 13 different TCR $\alpha$-chains utilized TRAV genes other than TRAV10 and these paired with a range of TRAJ genes, including TRAJ8, 24, 27, 30, 44, 48 and 52. These TRAJ segments displayed very limited sequence identity with the TRAJ18 gene segment, and minimal intersequence or inter-donor similarity (Table 1). The CDR $1 \alpha$ and $\mathrm{CDR} 2 \alpha$ loops displayed notable sequence variability, and moreover, on account of variable N-region additions and deletions, the length of the CDR $3 \alpha$ loop varied from 10 to 14 amino acids among the TRBV25-1 ${ }^{-}$subset, compared with the highly restricted CDR3 $\alpha$ of both the TRAV10 ${ }^{-}$ TRBV25-1 ${ }^{+}$and TRAV $10^{+}$TRBV25-1 ${ }^{+}$subsets, where $8 /$ 8 and 11/11 clones, respectively, had an invariant CDR $3 \alpha$ length of 13 residues (Table 1). In addition, the TCR $\beta$-chain gene usage was highly diverse, and included TRBV2, 4-1, 6-5, $7-8,11-2,12-5,20-1$ and 28 , along with diverse CDR3 $\beta$ 


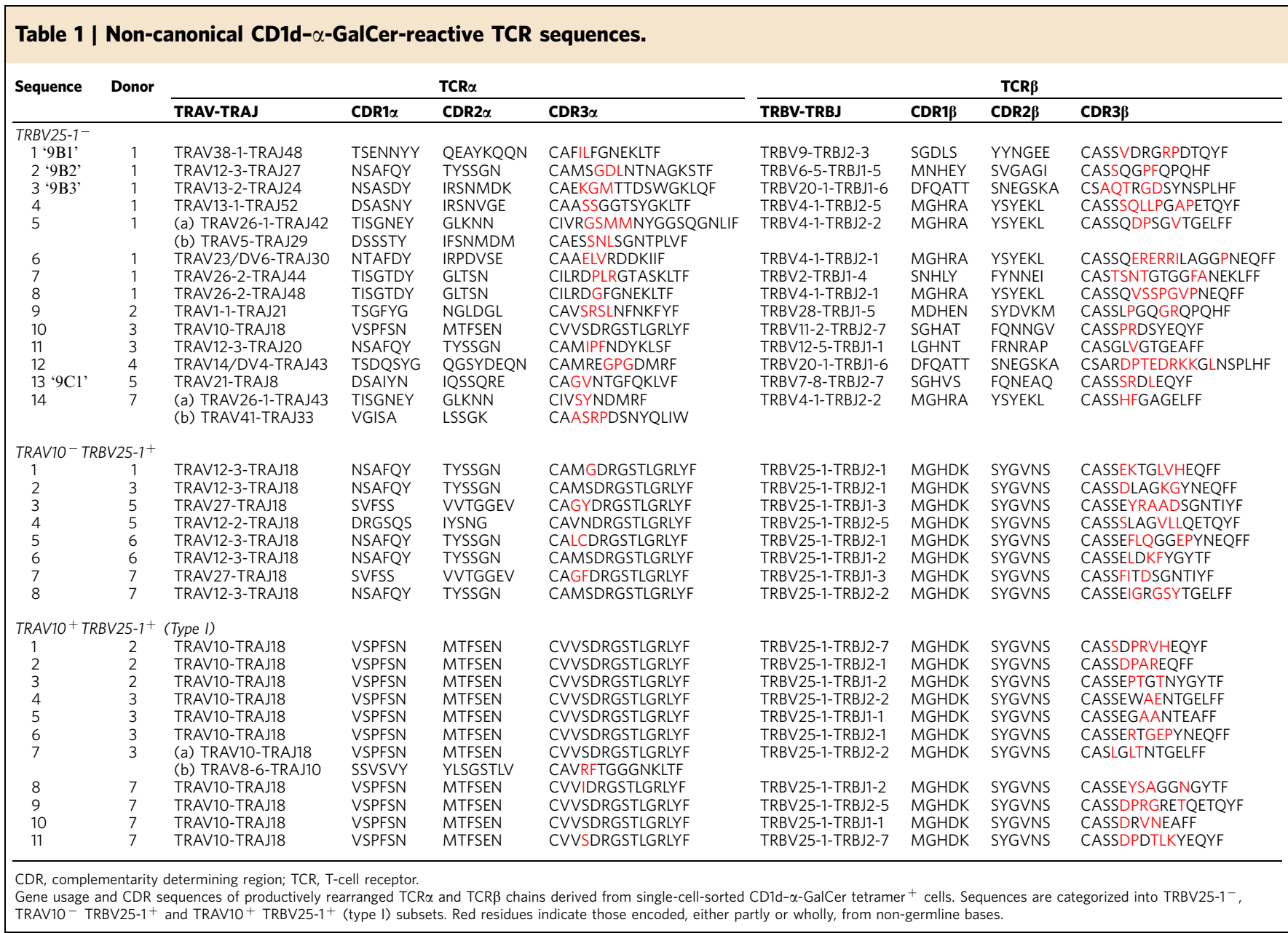

sequence and length (Table 1), and no identical clones were identified between separate donors. Accordingly, the CD1d$\alpha$-GalCer-reactive T-cell compartment is not only comprised of dominant TRAV $10^{+}$TRAJ $18^{+}$TRBV25-1 ${ }^{+}$and subdominant TRAV10- ${ }^{-}$RAJ18 ${ }^{+}$TRBV25-1 + 'public' repertoires, but in many cases, it also includes diverse TRAV $10^{-}$ TRAJ18- TRBV25-1 - 'private' TCR repertoires. We refer to these latter cells as 'atypical' NKT cells.

Differing patterns of Ag reactivity. A feature of the type I NKT TCR is that it not only reacts with $\alpha$-GalCer, but also imbues reactivity to a range of other self and foreign ligands. To establish the Ag-reactivity profile of atypical NKT cells, we stained CD1d- $\alpha$-GalCer tetramer-enriched and expanded PBMC samples from healthy donors with a panel of CD1d-Ag tetramers, and compared the TRBV25-1 ${ }^{+}$type I and TRBV25-1 ${ }^{-}$atypical NKT cells within each donor. While all type I NKT cells bound to $\alpha$-GalCer and $\alpha$-GlcCer-loaded CD1d, many of the atypical NKT cells failed to stain with $\alpha$-GlcCer-loaded CD1d tetramers (Fig. 2a). As we have previously published ${ }^{12}$, human type I NKT cells exhibited a strong dependence on the $3^{\prime}-\mathrm{OH}$ moiety of $\alpha$-GalCer as evidenced by their lack of reactivity to $3^{\prime}$-deoxy $\alpha$-GalCer. However, subsets of atypical NKT cells in donors 1 and 4 clearly tolerated this substitution (Fig. 2a). Differences between the Ag-reactivity profile of type I and atypical NKT cells were also evidenced using the $\mathrm{OCH}$ analogue of $\alpha$-GalCer, which has a truncated sphingosine chain. While this analogue is only poorly recognized by type I NKT cells, some subsets of atypical NKT cells, such as those in donor 1 and donor 3 , still recognized this
Ag (Fig. 2a). Thus, the diverse TCR expression by atypical NKT cells facilitates an altered and mixed pattern of CD1d-Ag reactivity compared with type I NKT cells.

To confirm the non-canonical TRBV25-1 ${ }^{-}$atypical NKT cell TCRs (Table 1) were indeed CD1d-restricted, we generated a panel of Jurkat T-cell lines transduced with TRBV25-1 ${ }^{-}$TCRs and examined their ability to bind CD1d tetramers loaded with a range of lipid Ags. We selected four TRBV25-1 - TCRs that represented a cross-section of the TCR $\alpha$ and TCR $\beta$ chain usage: clones 9C1 (TRAV2 $1^{+}$TRAJ8 ${ }^{+}$TRBV7- $8^{+}$; Table 1 , sequence \#13); 9B1 (TRAV38-1 ${ }^{+}$TRAJ48 ${ }^{+}$TRBV9; Table 1, sequence \#1); 9B2 (TRAV12-3 ${ }^{+}$TRAJ27 ${ }^{+}$TRBV6- $^{+}$; Table 1 , sequence \#2); 9 B3 (TRAV13-2 ${ }^{+}$TRAJ2 $4^{+}$TRBV20-1 ${ }^{+}$; Table 1 , sequence \#3) and two controls, namely a Jurkat pHLA-specific irrelevant TCR $\left(\mathrm{TRAV}_{17}{ }^{+} \mathrm{TRBV}^{+} 6^{+}\right.$) and an SKW3 $\mathrm{TRAV} 0^{+} \mathrm{TRAJ}_{18}{ }^{+}$ TRBV25-1 ${ }^{+}$type I NKT TCR $^{+}$cell line (SKW3.NKT15) (Fig. 2b). As expected, the pHLA-specific TCR did not bind to CD1d-Ag, while the SKW3.NKT15 cell line bound to CD1d- $\alpha$ GalCer, but not CD1d tetramer loaded with endogenous Ags (Fig. 2b). The 9C1, 9B1, 9B2 and 9B3 Jurkat cell lines all bound to the CD1d- $\alpha$-GalCer tetramer, but not to CD1d-endo, thereby confirming the CD1d-restriction and $\alpha$-GalCer reactivity of these TCRs isolated from human PBMCs (Fig. 2b). While the SKW3.NKT15 cell line could readily bind CD1d- $\alpha$-GlcCer, the atypical NKT TCRs did not tolerate this substitution, suggesting clear differences in how the atypical NKT TCRs interacted with the glycosyl headgroup compared with type I NKT TCRs (Fig. 2b). Similar to the trends in Fig. 2a, these cell lines exhibited a differential pattern of reactivity to the $\alpha$-GalCer analogues 
$3^{\prime}$-deoxy- $\alpha$-GalCer, $4^{\prime}$-deoxy- $\alpha$-GalCer and OCH (Supplementary Fig. 2).

Type I NKT cells can recognize $\beta$-linked self-ligands by moulding these ligands into a structural conformation resembling their $\alpha$-linked counterparts, albeit with reduced affinity ${ }^{25}$. Notably, in contrast to the type I SKW3.NKT15 cell line, we detected clear reactivity of Jurkat.9B1 and Jurkat.9B2 cell lines to $\beta$-GlcCer (Fig. $2 b$ ). This $\beta$-GlcCer reactivity, in the absence of

a

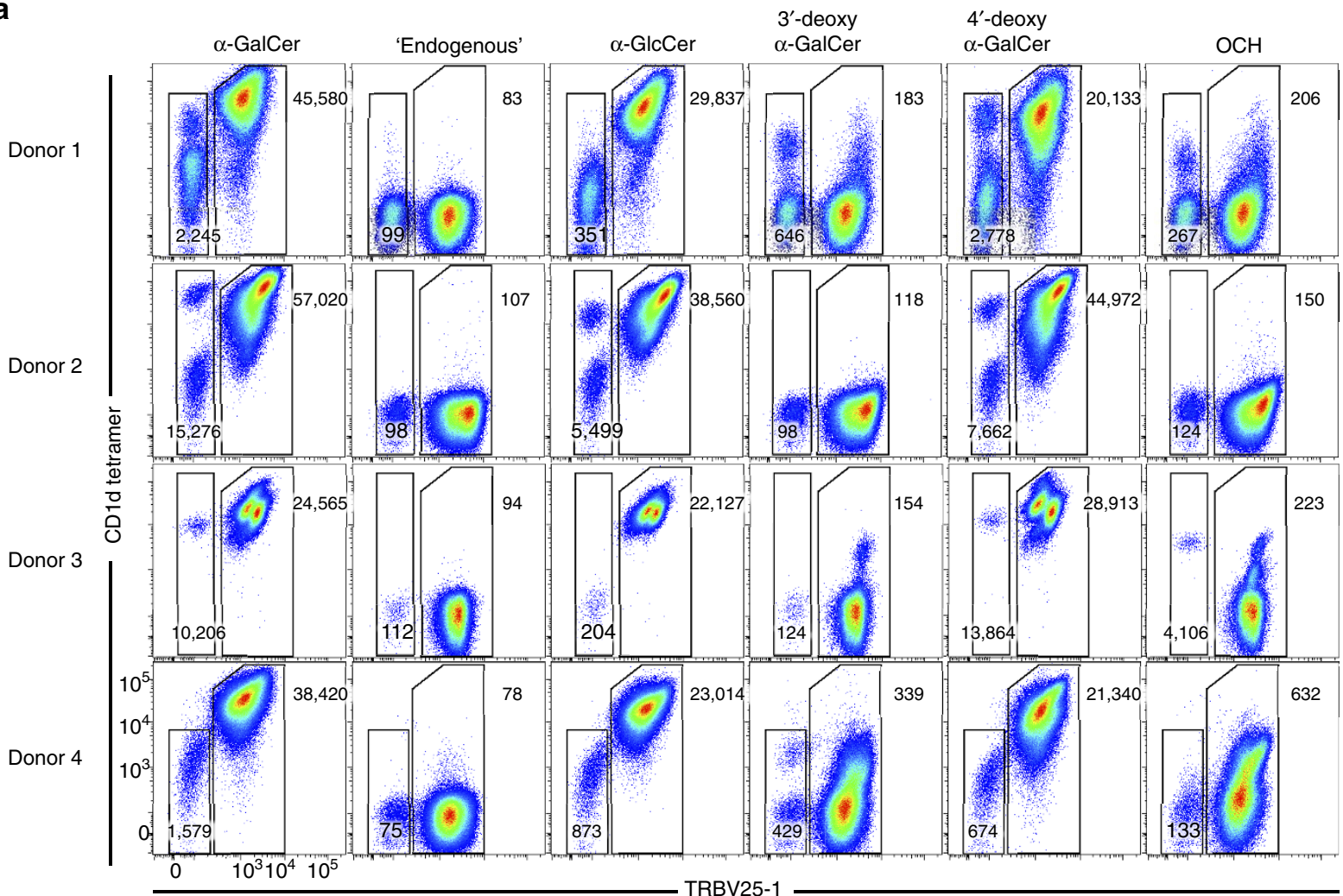

b

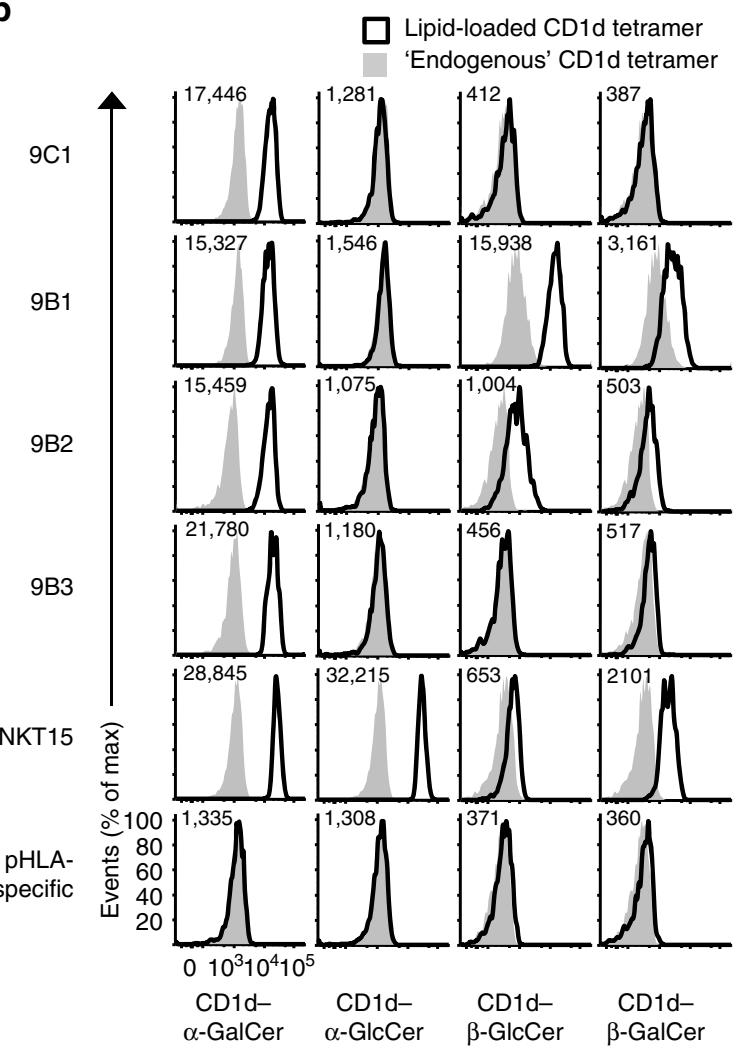

C

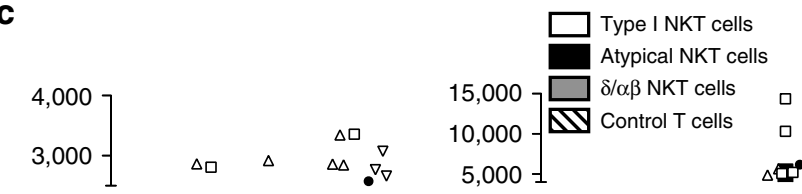

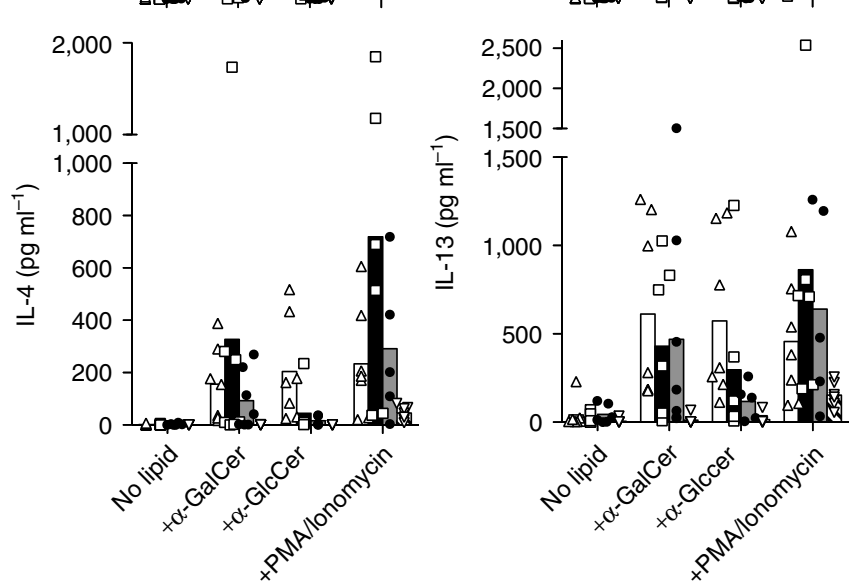


$\alpha$-GlcCer reactivity, is an indication that these atypical NKT TCRs were not reacting with any potential $\alpha$-GlcCer contamination within the $\beta$-GlcCer preparation ${ }^{39}$. These 9B1 and 9B2 TCRs also reacted to a lesser extent with $\beta$-GalCer (Fig. 2b), but none reacted with the type II NKT cell ligand sulfatide or the ganglioside GD3 (Supplementary Fig. 2). In addition, and in contrast to human type I NKT cells, there was no cross-species reactivity of any of these atypical NKT TCRs TCRs towards mouse CD1d- $\alpha$-GalCer (Supplementary Fig. 2). Therefore, non-canonical TRBV25-1 ${ }^{-}$NKT cell TCRs are capable of recognizing a diverse array of both $\alpha$ - and $\beta$-linked lipid Ags, with a spectrum and hierarchy of reactivity that is distinct from typical type I NKT cells.

To test the Ag responsiveness of atypical NKT cells, we isolated CD1d- $\alpha$-GalCer tetramer ${ }^{+}$TRBV25-1 ${ }^{-}$cells from PBMC by flow cytometric sorting, and then in vitro-expanded these cells with anti-CD3/CD28 in the presence of irradiated allogeneic PBMC for 2 weeks. Using this approach, seven out of eight donors had a clear population of atypical NKT cells after expansion, as well as the recently described CD1d- $\alpha$-GalCer tetramer ${ }^{+}$TRDV $1^{+} \delta / \alpha \beta$ NKT cells ${ }^{40}$ (Supplementary Fig. 3), with typical yields of $\sim 10^{4}-10^{6}$ cells for each subset per donor, after expansion. We re-sorted these populations, along with type I NKT cells (CD1d- $\alpha$-GalCer tetramer ${ }^{+}$TRBV25-1 ${ }^{+}$) and control (CD1d- $\alpha$-GalCer tetramer $\left.{ }^{-}\right) \mathrm{T}$ cells derived from the same cultures, and measured cytokine production after a $24 \mathrm{~h}$ challenge with different lipid Ag in the presence of CD1dexpressing APCs. Consistent with their tetramer reactivity, atypical NKT cells from five out of seven donors elicited a clear response following challenge with $\alpha$-GalCer, producing both Th1(IFN- $\gamma$, IL-2) and Th2- (IL-4, IL-13) type cytokines, compared with control cultures containing APCs alone (Fig. 2c). Both type I (seven out of seven donors) and $\delta / \alpha \beta$ (six out of seven donors) NKT cells responded in a similar fashion, however as expected, the control T cells did not respond to any lipid Ag (none of the seven donors) despite responding to PMA/ionomycin. Consistent with the tetramer-staining patterns, most atypical NKT cells exhibited reduced reactivity to $\alpha$-GlcCer compared with type I NKT cells. Thus, these data confirm that atypical NKT cells can respond to glycolipid Ag presented by CD1d with diverse cytokine production, similar to type I NKT cells.

Next, using CD69 upregulation as a marker of functional activation, we examined the ability of the transduced Jurkat.NKT cell lines to be activated in the presence of C1R cells expressing CD1d plus defined Ag. Following overnight co-culture with C1R cells expressing intermediate or high levels of CD1d, but not $\mathrm{CD}^{-} \mathrm{d}^{-} \mathrm{C} 1 \mathrm{R}$ WT cells, all the atypical Jurkat.NKT cell lines showed clear signs of activation (Fig. 3a). This was despite no obvious binding to the CD1d-endogenous tetramers (Fig. 2b), suggesting the activation assays were more sensitive than the tetramer-based assays. This also confirmed that these atypical NKT TCRs are capable of initiating cellular activation following TCR ligation by CD1d-Ag. Addition of graded concentrations of
$\alpha$-GalCer to these co-cultures resulted in greater activation of the Jurkat.9C1, 9B1 and 9B3 cell lines, yet only appeared to marginally enhance activation of the Jurkat.9B2 cell line (Fig. 3b). Thus, these data show that non-canonical TRBV25-1atypical NKT cell TCRs confer functional reactivity to CD1d, but they also demonstrate diverse and distinct patterns of $\mathrm{Ag}$ reactivity compared with TRAV $10^{+}$TRAJ $18^{+}$type I NKT cells.

Affinity towards CD1d-Ag. Using surface plasmon resonance (SPR), we next determined the affinity of two atypical NKT TCRs from clones $9 \mathrm{C} 1$ and $9 \mathrm{~B} 2$, towards CD1d bound to $\alpha$-GalCer and variants thereof. These two TCRs were selected based on their contrasting Ag reactivity profiles, whereby the 9C1 TCR demonstrated a strong dependence on $\alpha$-GalCer for activation, whereas the 9B2 TCR, whilst still reactive to CD1d- $\alpha$-GalCer tetramers, demonstrated an auto-reactive profile that was associated with less Ag-specific activation. We expressed, refolded and purified the soluble ectodomains of both TCRs to high yields, and passed them over CD1d-Ag coupled to a sensor chip. The 9C1 and 9B2 TCRs did not bind, or bound very poorly, to CD1d-endogenous tetramers respectively, consistent with the tetramer-binding data (Fig. 4). The 9C1 TCR and 9B2 TCR both bound to CD1d- $\alpha$-GalCer with an affinity $\left(K_{\mathrm{D}}\right)$ of $3.9 \mu \mathrm{M}$ and $4.0 \mu \mathrm{M}$ respectively, values that, while comparable to many TCR-pMHC interactions, were weaker than the affinity of the canonical type I NKT TCR (NKT15) towards CD1d- $\alpha$-GalCer $\left(K_{\mathrm{D}}=0.19 \mu \mathrm{M}\right)$ (Fig. 4). The affinity of the 9C1 and 9B2 TCRs towards CD1d-3'-deoxy- $\alpha$-GalCer $\left(K_{\mathrm{D}}=1.4 \mu \mathrm{M}\right.$ and $3.6 \mu \mathrm{M}$, respectively) was comparable or moderately higher than that of CD1d- $\alpha$-GalCer (Fig. 4). This is in stark contrast to the NKT15 TCR, which bound with much lower affinity to CD1d-3'-deoxy$\alpha$-GalCer $\left(K_{\mathrm{D}}=4.7 \mu \mathrm{M}, \sim 20 \text {-fold reduction) (Fig. } 4\right)^{12,26}$. Conversely, the 9C1 TCR exhibited a markedly reduced affinity $\left(K_{\mathrm{D}}>100 \mu \mathrm{M}\right)$ towards the $4^{\prime}$-deoxy- $\alpha$-GalCer analogue, while there was no negative impact of this analogue on NKT15 or 9B2 TCR binding (Fig. 4). Consistent with tetramer staining and functional studies, $\alpha$-GlcCer was bound with much lower affinity by $9 \mathrm{C} 1 \mathrm{TCR}$ and 9B2 TCR $\left(K_{\mathrm{D}}>100 \mu \mathrm{M}\right.$ and $19 \mu \mathrm{M}$, respectively), yet was well-tolerated by NKT15 TCR $\left(K_{\mathrm{D}}=0.12 \mu \mathrm{M}\right)$ (Fig. 4). The recognition of $4^{\prime}$-deoxy- $\alpha$-GalCer but not $\alpha$-GlcCer by 9B2 TCR implies that the equatorial $4^{\prime}-\mathrm{OH}$ group of $\alpha$-GlcCer may cause a conformational change in CD1d and/or the lipid headgroup, which is not tolerated by $9 \mathrm{~B} 2$. Thus, while the atypical NKT TCRs and type I NKT TCRs are reactive towards $\alpha$-GalCer, they clearly differ in their fine specificity towards CD1d-restricted Ags.

Overview of atypical NKT TCR ternary complexes. Next, to establish how atypical NKT TCR usage manifested in CD1d-Ag recognition, we determined the crystal structures of the 9C1 TCR-CD1d- $\alpha$-GalCer and 9B2 TCR-CD1d- $\alpha$-GalCer ternary complexes to 2.5 and $3.1 \AA$ resolution, respectively (Supplementary Tables 1-3, Supplementary Fig. 4). The 9C1

Figure 2 | Lipid reactivity of atypical TRBV25-1 - NKT cell lines. (a) CD1d tetramer staining of CD1d- $\alpha$-GalCer-reactive cells enriched and expanded from PBMCs from four healthy human donors. Plots show TRBV25-1 versus CD1d tetramers loaded with $\alpha$-GalCer (C24:1), 'endogenous' antigen, $\alpha$-GlcCer, 3'deoxy- $\alpha$-GalCer, 4'-deoxy- $\alpha$-GalCer or OCH. Data show one of two representative experiments. (b) Histograms depicting human CD1d-lipid antigen tetramer staining (white histograms) of $\mathrm{CD} 3^{+}$Jurkat T-cell lines transduced with the 9C1,9B1, 9B2, 9B3 atypical NKT cell TCRs or with the NKT15 type I NKT cell TCR or an irrelevant pHLA-specific TCR control, overlaid with 'endogenous' tetramers (grey histograms). Numbers in each histogram represent CD1d-lipid tetramer mean fluorescence intensity. Data are representative of two separate experiments. (c) Graphs depict the mean IFN- $\gamma$, IL-2, IL-4 and IL-13 concentrations in culture supernatants of $4-5 \times 10^{3}$ in vitro-expanded/purified CD1d- $\alpha$-GalCer tetramer ${ }^{+}$TRBV25-1 $^{+}$(type I NKT, white bars), CD1d- $\alpha$-GalCer tetramer ${ }^{+}$TRBV25-1- (atypical NKT, black bars), CD1d- $\alpha-G a l C e r$ tetramer ${ }^{+}$TRDV1 $^{+} \gamma \delta$ TCR ${ }^{-}(\delta / \alpha \beta$ NKT, grey bars), and CD1d- $\alpha$-GalCer tetramer ${ }^{-}$(control T cells, hashed bars), with different lipid Ag $\left(0.5 \mu \mathrm{g} \mathrm{ml}^{-1}\right.$ ) in the presence of K562.CD1d APCs or PMA/ionomycin for $24 \mathrm{~h}$. Data are representative of $n=5-7$ donors, with each symbol depicting a separate donor (each symbol derived from $n=1-2$ technical replicates). Data are pooled from two independent experiments. 
a

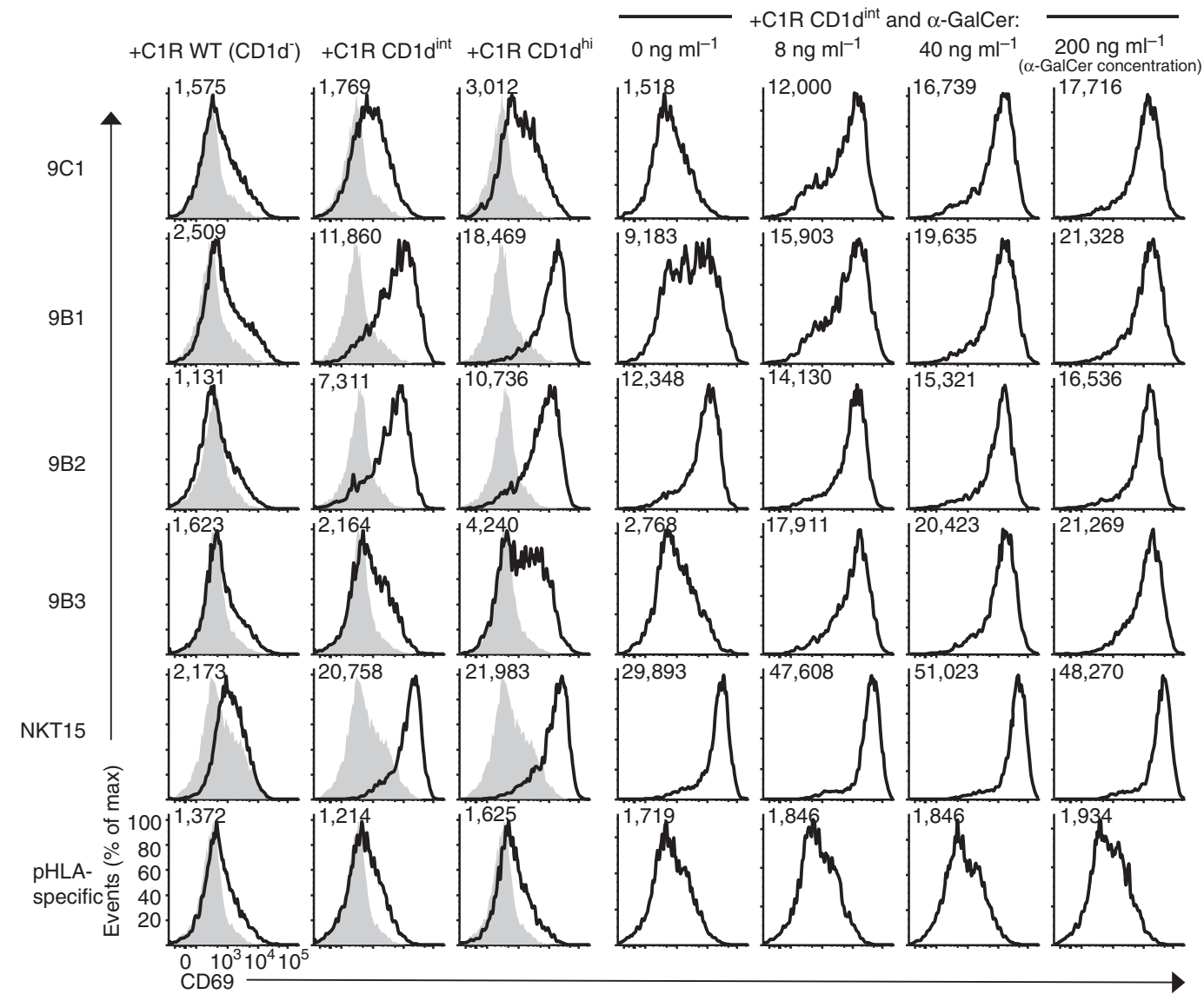

b

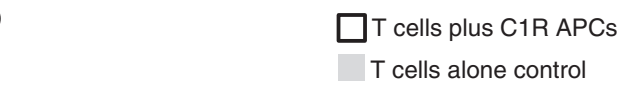

$\overline{0 \mathrm{ng} \mathrm{ml}^{-1}}+\begin{gathered}\mathrm{C} 1 \mathrm{R} \mathrm{CD} 1 \mathrm{~d}^{\mathrm{int}} \\ 8 \mathrm{ng} \mathrm{ml}^{-1}\end{gathered}$ ) 

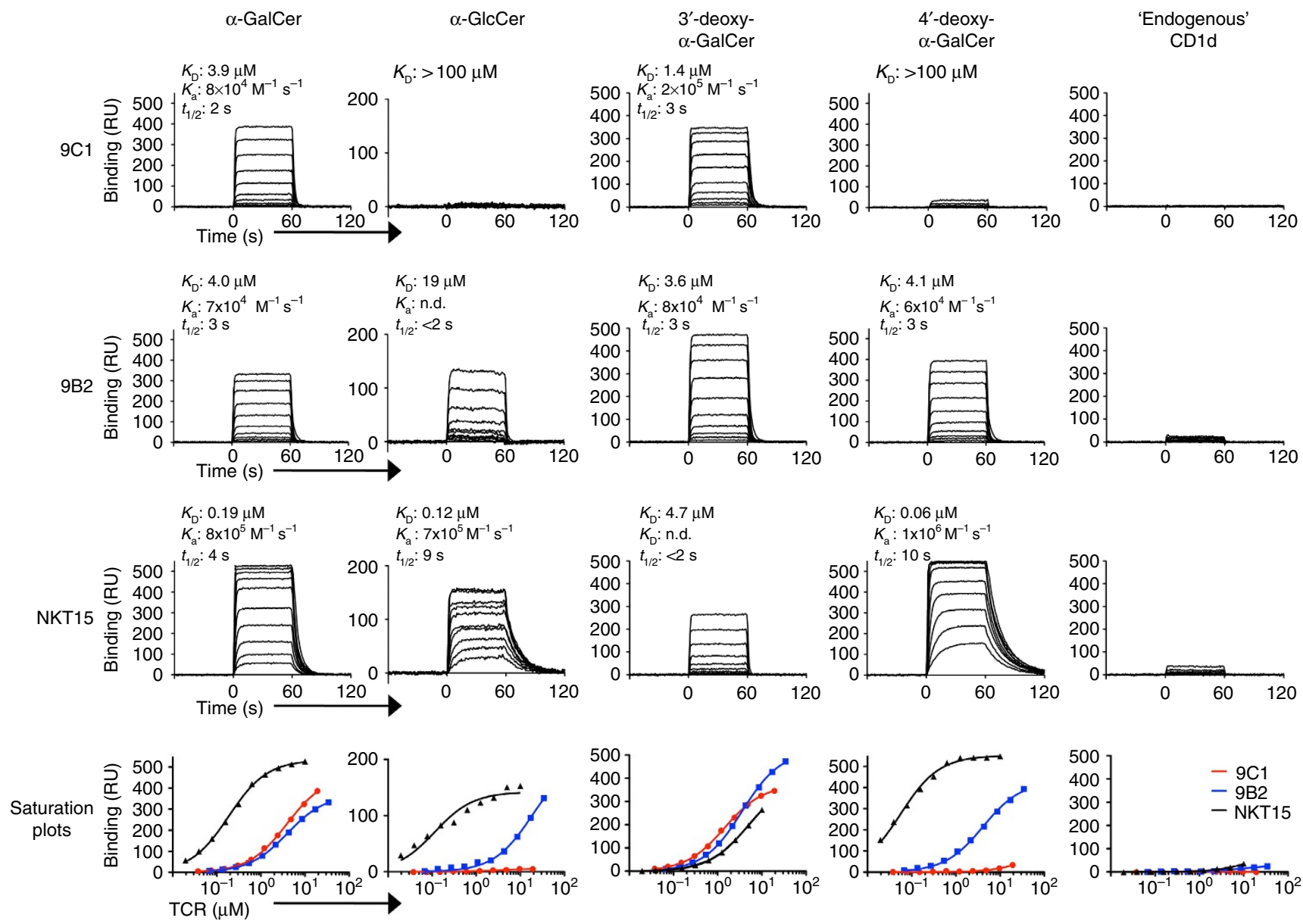

Figure 4 | Affinity of non-canonical TRBV25-1 - NKT cell TCRs to CD1d-Ag. The affinity of TCR-CD1d-Ag interactions were determined by surface plasmon resonance, by measuring the binding of graded concentrations of soluble $9 \mathrm{C1}(19-0.038 \mu \mathrm{M}), 9 \mathrm{~B} 2(34-0.067 \mu \mathrm{M})$, and a type I NKT cell control $(N K T 15,10-0.02 \mu \mathrm{M})$, to human CD1d loaded with $\alpha$-GalCer, $\alpha$-GlcCer, $3^{\prime}$-deoxy $\alpha$-GalCer, $4^{\prime}$-deoxy $\alpha$-GalCer or CD1d-endogenous. Saturation plots for $9 \mathrm{C} 1$ (red), 9B2 (blue) and NKT15 (black) versus each respective ligand are shown in the lower panels. $K_{\mathrm{D}}$, dissociation constant; $K_{\mathrm{a}}$, association rate; $t_{1 / 2}$ half-life. Results are representative of two similar experiments.

from the $\alpha 2$-helix (spanning from Trp153-Trp160), and the $\alpha 1$-helix (spanning Thr65-Val72). As such, the CDR3 $\alpha$ was wedged within the Ag-binding cleft, with Thr109 $\alpha$ stacking against Trp160 and hydrogen bonding to Thr157 of CD1d, while Gln $112 \alpha$ formed vdw contacts with Val72 (Supplementary Table 2) and hydrogen bonded to His68 of CD1d (Fig. 6a, left panel). The interactions between the 9C1 TRBV7-8-encoded TCR $\beta$-chain and CD1d were more limited, being largely dominated by the CDR2 $\beta$ (BSA 14\%) and neighbouring framework regions ligating to the $\alpha 1$-helix of CD1d. Here Gln57 $\beta$ and Asn $58 \beta$ hydrogen bonded to Ser76 and Arg79 of CD1d, respectively, while Leu66 $\beta$ packed against Val72 (Fig. 6a, middle panel).

In the 9B2 TCR ternary complex, the TCR $\alpha$-chain chain mediated most of the interactions with CD1d- $\alpha$-GalCer (BSA $64 \%$ ), within which the CDR3 $\alpha$ loop, the characteristics of which are also distinct from the TRAJ18-encoded CDR3 $\alpha$ loop, was the principal contributor to the interface (32\% BSA) (Figs 5b,6b left panel). The CDR $1 \alpha$ (BSA 15\%) and CDR2 $\alpha$ (BSA 12\%) made exclusive contacts with the $\alpha 2$-helix of CD1d, whereupon Tyr $32 \alpha$ wedged between Trp153 and Trp160 and hydrogen bonded to Thr157 and Trp160; Trp160 also packed against Gln31 $\alpha$ (Fig. 6b left panel). Trp153 of CD1d also stacked against Tyr57 $\alpha$, which occupied the same location as Tyr31 $\alpha$ from the CDR $1 \alpha$ loop of the 9C1 TCR (Fig. 7). The CDR2 $\alpha$ loop interactions were enhanced by the neighbouring framework residue, Lys $82 \alpha$, saltbridging to Glu156 of CD1d (Supplementary Table 3). Central to the CDR3 $\alpha$ loop-mediated contacts was Leu110 $\alpha$, which sat within the central axis of the Ag-binding cleft and formed vdw contacts with Asn62, Leu66, Trp160 and Thr165 (Fig. 6b, left panel and Supplementary Table 3). Supplementing these interactions was Ala1 $14 \alpha$, which was packed against the $\alpha 1$-helix and the main chain carbonyls of Leu110 $\alpha$, and Ala114 $\alpha$ forming hydrogen bonds with Asn62 and Thr65 of CD1d, while Asn111 $\alpha$ hydrogen bonded to Gln168 (Fig. 6b). Regarding the 9B2 TCR $\beta$-chain interactions, the CDR3 $\beta$ loop was the principal contributor to this interface (BSA 20\%), as the CDR1 $\beta$ and CDR2 $\beta$ loops played lesser roles (7 and 5\% BSA respectively). Here Tyr31 $\beta$, Val57 $\beta$ and Ile61 $\beta$ aligned to form a focused interaction site spanning residues $64-68$ on the $\alpha 1$-helix of CD1d (Supplementary Table 3 ). The CDR3 $\beta$ loop was positioned between the $\alpha 1$ - and $\alpha 2$-helices, where Phe111 $\beta$ plugged a hydrophobic-lined cavity formed by Thr65, His68, Ile69 and Trp160 (Fig. 6b, middle panel). Notably, Phe111 $\beta$ and Gln112 $\beta$ of the 9B2 TCR mirrored the position of Phe111 $\alpha$ and Gln $112 \alpha$, respectively, from the 9C1 TCR (Figs $6 \mathrm{~b}$ and 7). In both 9C1 TCR and 9B2 TCR ternary complexes, the three $\operatorname{CDR} \alpha$ loops and the CDR3 $\beta$ are involved in mediating the CD1d interactions. This is in clear contrast to the classical NKT15 type I ternary complex, whereby only the CDR3 $\alpha$ contacted the CD1d molecule while the CDR3 $\beta$ was not involved in any interactions with CD1d (Fig. 6c, left and middle panels). Interestingly, while there were notable differences in the sequences of the 9C1 and 9B2 TCRs 

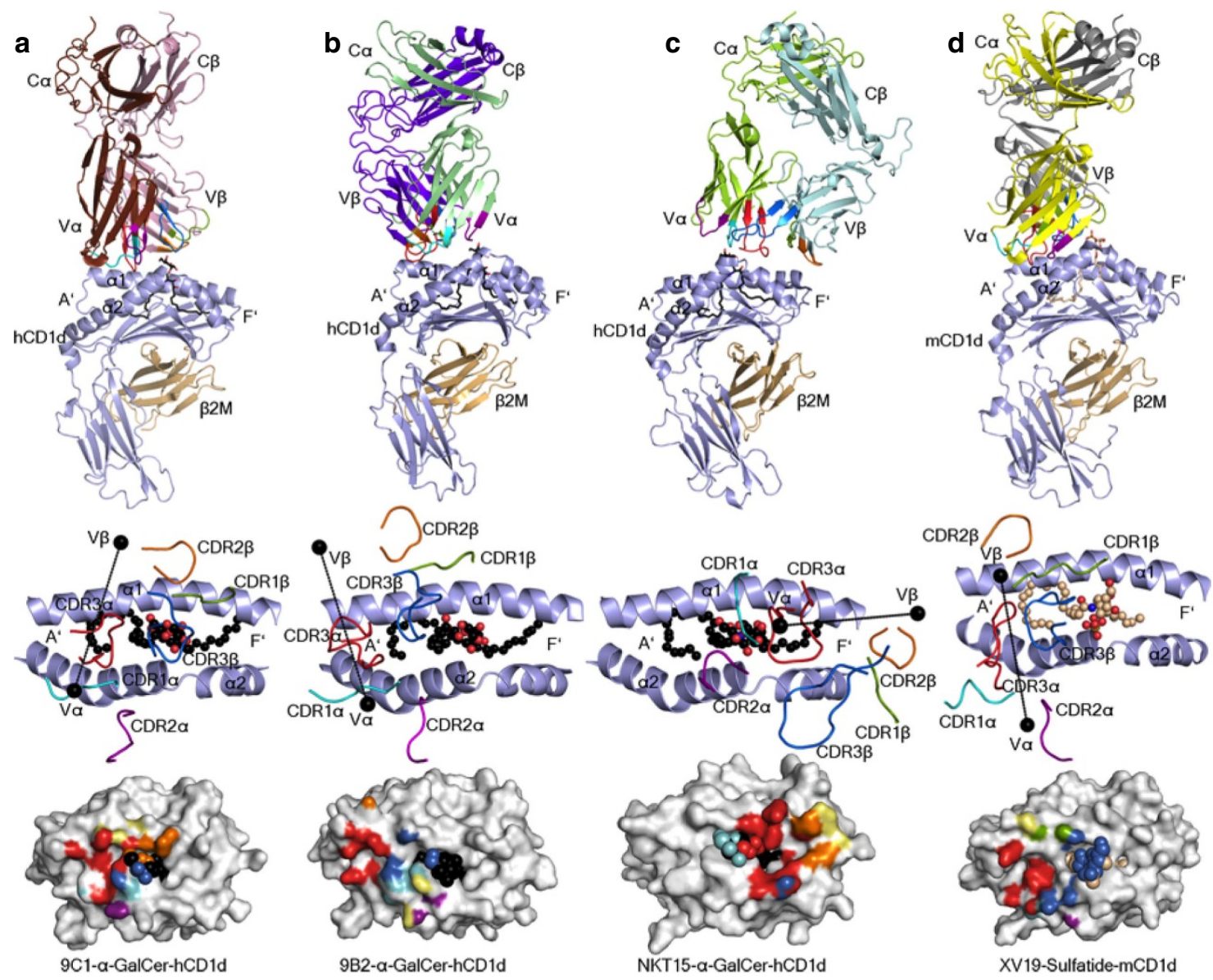

Figure 5 | Overview of the docking of atypical NKT TCR ternary complexes. Ternary complexes of (a) human 9C1 TCR-CD1d- $\alpha-G a l C e r,(b) 9 B 2$ TCR-CD1d- $\alpha$-GalCer, (c) NKT15 TCR-CD1d- $\alpha$-GalCer (PDB code 2PO6 (ref. 27) and (d) mouse XV19 TCR-CD1d-sulfatide (PDB code 4EI5 (ref. 36). Top panels depict an overview of each structure, middle panels illustrate the TCRs docking onto CD1d and lower panels show the TCR footprints on the CD1d-Ag molecular surface. The CD1d and $\beta 2$-microglobulin molecules are coloured in light blue and light brown, respectively. 9 C1 TCR $\alpha$, brown; 9 C1 TCR $\beta$, light pink; 9B2 TCR $\alpha$, light green; 9B2 TCR $\beta$, purple; NKT15 TCR $\alpha$, green; NKT15 TCR $\beta$, cyan; XV19 TCR $\alpha$, yellow; XV19 TCR $\beta$, grey. The CDR loops are coloured as follows: CDR1 $\alpha$, aqua; $C D R 2 \alpha$, purple; $C D R 3 \alpha$, red; CDR1 $\beta$, green; CDR2 $\beta$, orange; CDR3 $\beta$, blue. The $\alpha$-GalCer and sulfatide are coloured in black and light brown sticks (top panel), or black and light brown spheres (middle and lower panels), respectively. In the middle panels, the centre of mass of the respective TRAV and TRBV variable domains are shown as black spheres. In the bottom panels, the molecular surface of CD1d is coloured in light grey.

and respective interatomic TCR-CD1d contacts, there was nevertheless a degree of focused structural mimicry within these atypical type I NKT TCR-CD1d- $\alpha$-GalCer ternary complexes (Fig. 7). Thus, atypical and type I NKT TCRs engaged CD1d- $\alpha$-GalCer in a markedly different manner.

Interactions with $\boldsymbol{\alpha}$-GalCer. In both the 9C1 and 9B2 TCR ternary complexes, the electron density for $\alpha$-GalCer was unambiguous (Supplementary Fig. 4a,b). While the positioning of $\alpha$-GalCer was very similar within the ternary complexes of the atypical NKT TCR and the type I NKT TCR complexes, the ensuing interactions with the lipid Ag were markedly different. In the 9C1 TCR ternary complex, both the $\alpha$ - and $\beta$-chains mediated lipid Ag recognition, with direct interactions arising from the $\operatorname{CDR} 3 \alpha, \operatorname{CDR} 2 \beta$ and CDR3 $\beta$ loops. To enable this, the CDR3 $\beta$ residues (Ser108 $\beta$, Arg109 $\beta$, Asp110 $\beta$ and Leu111 $\beta$ ) and Gln $112 \alpha$ in the CDR $3 \alpha$ rearranged to accommodate the Ag (Supplementary Fig. 4d). Here, the main chain carbonyl of Arg $109 \beta$ hydrogen bonded to the $4^{\prime}-\mathrm{OH}$ of $\alpha$-GalCer, the latter of which also contacted Ser31 $\beta$ via a water-mediated hydrogen bond (Fig. 6a, right panel). Further, a water-mediated hydrogen bond between the $3^{\prime}-\mathrm{OH}$ and $\mathrm{Tyr} 31 \alpha$ was observed. The $6^{\prime}-\mathrm{OH}$ hydrogen bonded to Gln $112 \alpha$ and Gln57 $\beta$ (Fig. 6a) and interacted with the framework residue Tyr55 $\beta$ (Supplementary Table 2). While, in the 9B2 TCR ternary complex, the interactions with the $\alpha$-GalCer moiety were extremely limited, namely, Gln $112 \beta$ solely contacted the $6^{\prime}-\mathrm{OH}$ of $\alpha$-GalCer (Fig. $6 \mathrm{~b}$, right panel). Both these atypical NKT TCR- $\alpha$-GalCer contacts contrasted with that of the type I NKT TCR ternary complex. Here interactions with $\alpha$-GalCer were mediated only via the type I NKT TCR $\alpha$-chain, where the $2^{\prime}-\mathrm{OH}, 3^{\prime}-\mathrm{OH}$ and $4^{\prime}-\mathrm{OH}$ groups are closely sequestered by the $\operatorname{CDR} 1 \alpha$ and $\operatorname{CDR} 3 \alpha$ loops, while the $6^{\prime}-\mathrm{OH}$ moiety was solvent exposed (Fig. 6c, right panel).

Given the fundamental differences in the contacts with $\mathrm{Ag}$, we probed the importance of the 9C1 and 9B2 TCR residues that contacted the $\alpha$-GalCer moiety. To establish this, we undertook a mutagenesis/SPR approach on the 9C1 and 9B2 TCRs. For the 9C1 TCR, this included analysing the impact of nine mutants:

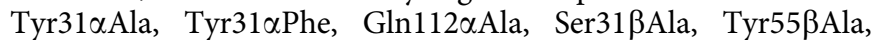
Tyr55 $\beta$ Phe, Gln57 $\beta A l a$, Arg109 $\beta$ Ala and Leu111 $\beta$ Ala, while for the 9B2 TCR, this involved Gln112 $\beta$ Ala mutant only (Table 2). For the 9C1 TCR, while the Ser31 $\beta$ Ala mutant had no effect, mutations of the residues contacting the $6^{\prime}-\mathrm{OH}$ of $\alpha$-GalCer, 


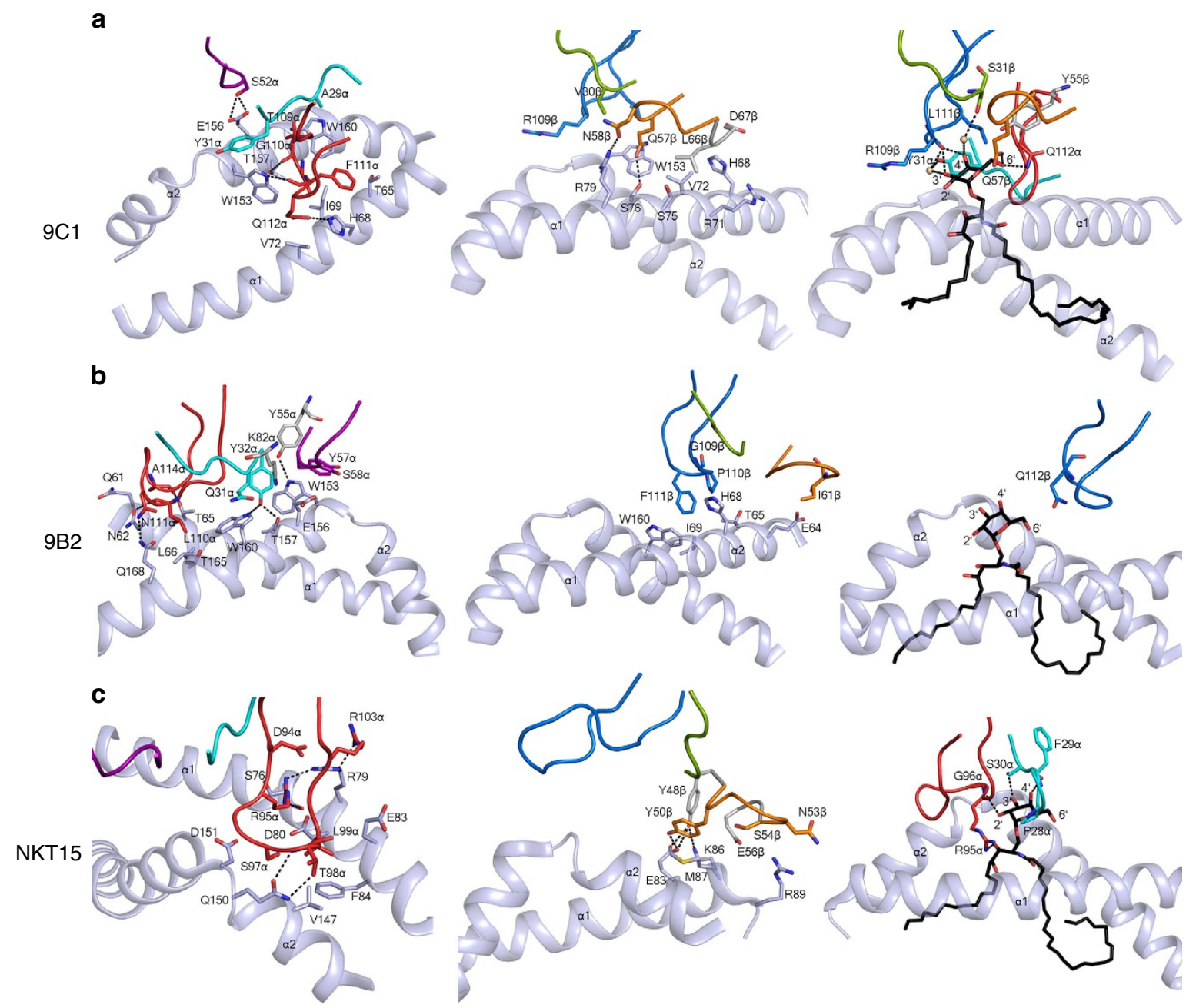

Figure 6 I Interactions at the CD1d-Ag-TCR interface. (a) Left panel, 9C1 TCR $\alpha$-chain interactions with CD1d; middle panel, 9 C1 TCR $\beta$-chain interactions with CD1d; right panel, 9C1 TCR interactions with $\alpha$-GalCer; (b) Left panel, 9B2 TCR $\alpha$-chain interactions; middle panel, 9B2 TCR $\beta$-chain interactions with CD1d; right panel, 9B2 TCR interactions with $\alpha$-GalCer; (c) Left panel, NKT15 TCR $\alpha$-chain interactions with CD1d; middle panel, NKT15 TCR $\beta$-chain interactions with CD1d; right panel, NKT15 TCR interactions with $\alpha$-GalCer. For clarity, only the hydrogen bonds are shown as black dashed lines and the $\alpha 1$ - and $\alpha 2$-helices of CD1d are shown as cartoon representation and coloured in light blue. CDR loops are coloured according to Fig. 5; spheres represent water molecules.

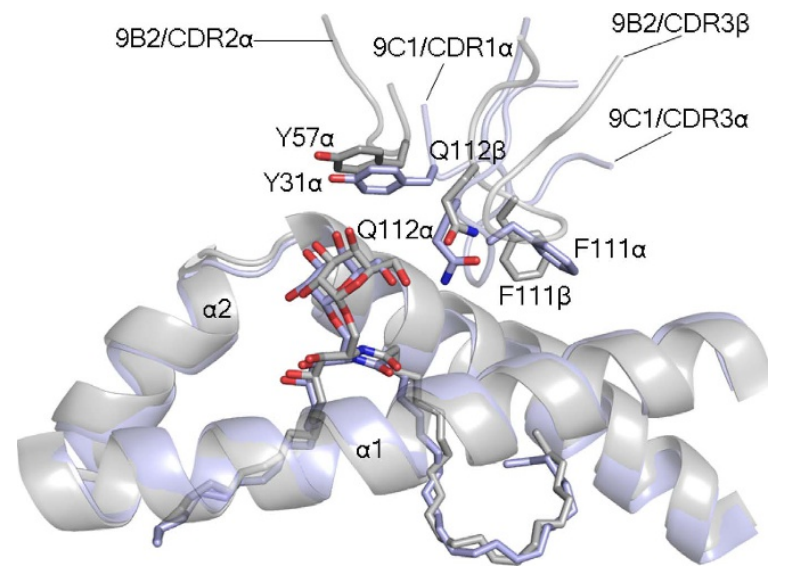

Figure 7 | Molecular mimicry between the $9 \mathrm{~B} 2$ and $9 \mathrm{C1}$

TCR-CD1d- $\alpha$-GalCer complexes. Superposition of the 9B2 and 9C1 TCR ternary complexes, coloured in grey and light blue, respectively. The superposition is based on the CD1d molecules of each complex. For clarity, only the CDR $1 \alpha / C D R 3 \beta$ of $9 \mathrm{C} 1$ and the CDR2 $\alpha / C D R 3 \alpha 9 B 2$ are shown.

\section{Table 2 | Affinity measurements of 9C1 and 9B2 TCR} mutants to CD1d- $\alpha$-GalCer.

\section{TCR}

9C1 WT

9C1 Tyr31 $\alpha$-Ala

9C1 Tyr31 $\alpha$-Phe

9C1 GIn112 $\alpha$-Ala

9C1 Ser31 $\beta$-Ala

9C1 Tyr55 $\beta$-Ala

9C1 Tyr55 $\beta$-Phe

9C1 GIn57 3 -Ala

9C1 Arg109ß-Ala

9C1 Leu1113-Ala

9B2 WT

9B2 GIn112 $\beta$-Ala

TCR, T-cell receptor.

Binding of soluble $9 \mathrm{C} 1$ and $9 \mathrm{~B} 2$ mutants to $C D 1 d-\alpha-G$ alCer, as determined by surface plasmon resonance. Dissociation constant $\left(K_{D}\right)$ values for 9 C1 WT, Tyr31 $\alpha$-Ala, Gln112 $\alpha$-Ala, Ser31 $\beta-A l a$, Arg109 $\beta$-Ala, Leu111 $\beta$-Ala and 9B2 WT represent the mean of two independent experiments, and $9 \mathrm{C} 1$ Tyr31 $\alpha$-Phe, Tyr55 $\beta$-Ala, Tyr $55 \beta$-Phe, Gln57 $\beta$-Ala and $9 \mathrm{~B} 2$ Gln112 $\beta$-Ala are derived from 
namely, Tyr55 $\beta$ Ala, Tyr55 $\beta$ Phe, Gln112 $\alpha$ Ala and Gln57 $\beta$ Ala impacted on the binding affinity relative to the wild-type 9C1 TCR. Although Leu111 $\beta$ interacted with the $\mathrm{C} 6$ and $4^{\prime}-\mathrm{OH}$ of the $\mathrm{Ag}$ via vdw contacts, the Leu111ßAla mutation completely ablated CD1d- $\alpha$-GalCer recognition. The effect of this mutant may be attributable to the major role Leu111 $\beta$ plays in contacting CD1d. Interestingly, while the Tyr31 $\alpha$ Ala mutant abrogated recognition, the Tyr $31 \alpha \mathrm{Phe} 9 \mathrm{C} 1$ variant increased the affinity for CD1d- $\alpha$-GalCer, presumably by reinforcing the hydrophobic character of the $9 \mathrm{C} 1 \mathrm{TCR}-\mathrm{CD} 1 \mathrm{~d}-\alpha-$ GalCer interface. For the $9 \mathrm{~B} 2$ TCR, the Gln112ßAla mutant resulted in a moderate reduction in affinity, but did not completely ablate binding. This suggests that mutating Gln $112 \beta$ to Ala might enable a compensatory interaction to form via another adjacent residue in the TCR $\beta$ chain (for example, Gln108 $\beta$ ); or alternatively, that the Gln112ßAla mutant of 9B2 is more permissive for binding of endogenous lipid Ags than the WT 9B2 protein, thus resulting in a higher level of autoreactivity. Therefore, contrasting modes of $\alpha$-GalCer-centric interactions exist between the atypical NKT TCRs and type I NKT TCRs.

\section{Discussion}

Human type I NKT cells are characterized by their expression of the semi-invariant (TRAV $10^{+}$TRAJ $18^{+}{ }^{+}$TRBV $25-1^{+}$) TCR and their strong reactivity to $\alpha$-GalCer presented by CD1d ${ }^{6}$. The type I NKT TCR resembles a pattern recognition receptor in that a universal docking mode underpins type I NKT TCR-CD1d-Ag recognition ${ }^{8,41}$. Our findings reveal that $C D 1 d-\alpha-$ GalCer reactive NKT cells neither have to utilize the semi-invariant TCR, nor do they necessarily have to recognize the resultant CD1d-Ag complex in the consensus type I NKT TCR-CD1d docking topology.

In humans, the type I NKT TCR recognizes a range of chemically diverse lipid Ags by docking over the $\mathrm{F}^{\prime}$-pocket of CD1d in a parallel manner ${ }^{42}$. Here the invariant TCR $\alpha$-chain contacts $\mathrm{CD} 1 \mathrm{~d}$ and the Ag, whereas the TCR $\beta$-chain contacts CD1d only. Central to this interaction is the TRAJ18-encoded CDR $3 \alpha$ loop, a highly polar loop that makes a number of complementary electrostatic interactions with CD1d- $\alpha-$ GalCer ${ }^{42}$. The importance of the TRAJ18 gene segment for type I NKT cell development is emphasized by the observations that TRAJ18deficient mice have markedly impaired NKT cell numbers ${ }^{43}$. However, there are exceptions to the use of the invariant TCR $\alpha$-chain by CD1d- $\alpha$-GalCer-reactive NKT cells. For example, populations of mouse TRAV13-3+ ${ }^{+} \mathrm{TRAJ} 50^{+}$and human TRAV10 $0^{-}$TRAJ18 ${ }^{+}$NKT cells have been described previously ${ }^{17,22,38}$. Furthermore, TCR sequencing of human TRAV10 ${ }^{-}$NKT cells showed that while most still expressed TRAJ18, some other TRAJ genes were used in addition to a number of other TCR TRBV genes ${ }^{21}$, although the specificity of these TCRs was not verified. Thus, while variations in the CD1d- $\alpha$-GalCer-reactive NKT cell repertoire can impact the functional responses and fine specificity towards some Ags, structural analysis of these interactions have nevertheless suggested that they do so under the confines of the consensus footprint on CD1d ${ }^{8}$.

As we had previously described a population of $\mathrm{CD} 1 \mathrm{~d}-\alpha-$ GalCer-reactive TRAV11-TRAJ18 ${ }^{-}$NKT cells in mice $^{19}$, we asked whether such a population of cells could exist in humans. Using $\alpha$-GalCer, we demonstrated a subset of NKT cells with diverse TCR $\alpha$ and $\beta$ chain usage. While diverse NKT TCR usage is generally a feature of type II NKT cells, the NKT cells identified here were reactive to the prototypic type I NKT cell Ag, $\alpha$-GalCer. This meant that these cells could neither be described as type I, nor type II NKT cells, and hence we presently termed that as atypical NKT cells. Notably, they were distinct from the previously described mouse 'V $\alpha 10$ ' $\left(\mathrm{TRAV} 13-3^{+}\right.$) NKT subset in that they utilized a diverse array of non-canonical $\operatorname{TCR} \alpha$ and TCR $\beta$ chain gene segments, therefore suggesting that no apparent mouse homologue of atypical NKT cells has been described. The TRBV25-1 ${ }^{-}$atypical NKT cells were distinct from type I and other, previously defined TRAV $10^{-}$ (but TRBV25-1 ${ }^{+}$) non-canonical NKT cells, in that they also did not utilize the TRAJ18 TCR gene segment. Thus, it appears that TRAJ18 and TRBV25-1 are strongly associated with, and may dictate, the archetypal type I NKT cell TCR parallel docking footprint, since in their absence the atypical NKT cell TCRs were able to adopt alternate docking strategies. The basis for the strong association between TRAJ18 and TRBV25-1 expression is unclear, although these TCR elements dominate the interactions with CD1d- $\alpha$ GalCer in type I NKT TCR complexes. This may indicate that, when used in concert, these TCR motifs preferentially support NKT cell selection criteria during T-cell development, or alternatively, facilitate preferential recognition of a stimulatory sub-class of endogenous $\mathrm{Ag}$. These findings also highlight the fact that diverse TCR usage can also be a feature of CD1d- $\alpha$-GalCer-reactive NKT cells. Notably, similar to type I NKT cells, these atypical NKT cells could respond to glycolipid Ag presented by CD1d with diverse cytokine production.

Importantly, this repertoire diversity also manifests in differing affinities and functional outcomes towards self- and foreign lipid Ags, in that these atypical NKT TCRs appeared to be of lower affinity to the type I NKT TCRs and also exhibited differing fine specificities. Surprisingly, such differences were attributable to the atypical NKT TCRs adopting a footprint on CD1d that was markedly different to that of consensus $\mathrm{F}^{\prime}$-pocket docking mode that has consistently been observed for all type I NKT TCRs to date. Namely, two representative atypical NKT TCRs, 9C1 and 9B2, both adopted distinct docking modes above the $\mathrm{A}^{\prime}$-pocket of CD1d, by binding in an orthogonal manner. These docking modes were reminiscent of the mouse type II NKT TCR (clone XV19) binding to CD1d presenting sulfatide, and moreover, the distribution of contacts across the CDR loops of these atypical NKT TCRs were more analogous to that of type II XV19 NKT TCR recognition ${ }^{36,37}$. This $\mathrm{A}^{\prime}$-pocket docking mode also resonated with the recently described $\gamma \delta$ TCR-CD1d-Ag complexes, although naturally the details of the interatomic contacts differed substantially ${ }^{22,44}$. In finding different solutions to interact with CD1d, it was interesting to note that molecular mimicry 'hot spots' underpinned 9C1 and 9B2 TCR recognition. Namely, 'aromatic motifs' within different regions of the TCRs were seen to play analogous roles in contacting CD1d, despite arising from different regions of the respective TCRs. Furthermore, the atypical NKT cell TCRs also adopted differing strategies to interact with $\alpha$-GalCer, with interactions via the $6^{\prime}-\mathrm{OH}$ of $\alpha$-GalCer featuring prominently in atypical NKT TCR recognition, in stark contrast to typical type I NKT TCR recognition where this motif is not involved in recognition ${ }^{8}$.

Our studies show that the human $\alpha \beta$ TCR, $\delta / \alpha \beta$ TCR and $\gamma \delta$ TCR repertoire is sufficiently flexible to recognize the same Ag-presenting molecule displaying the same $\mathrm{Ag}$ via a number of different mechanisms. Our findings imply that the TCR repertoire provides significant molecular scope for recognition of diverse lipid-based Ags in the context of CD1d. Given that $\alpha$-GalCer is being explored as a potential immunotherapeutic agent, and numerous analogues of $\alpha$-GalCer have been generated to improve the therapeutic efficacy of this $\operatorname{drug}^{8,45,46}$, it is important that we understand the impact of such modifications 
on the entire CD1d- $\alpha$-GalCer-reactive NKT TCR repertoire. Our findings have radically reshaped our understanding of NKT TCR recognition.

\section{Methods}

Accession numbers. The structures of 9B2 TCR-CD1d- $\alpha-\mathrm{GalCer}, 9 \mathrm{C} 1$ TCR-CD1d- $\alpha$-GalCer and 9C1 TCR were deposited in the RCSB Protein Data Bank (PDB) under the accession codes $4 \mathrm{WWK}, 4 \mathrm{WW} 2$ and $4 \mathrm{WW} 1$, respectively.

Flow cytometry. Blood samples from healthy blood donors were obtained from the Australian Red Cross Blood Service under agreement number 13-04VIC-07, and experiments were conducted in accordance with the University of Melbourne Human Research and Ethics committee guidelines (approval number 1035100). PBMCs were isolated by density gradient centrifugation (Histopaque-1077, Sigma). Cells were stained with CD3ع (UCHT1, eBioscience and Becton Dickinson), CD4 (RPA-T4, Becton Dickinson), CD8 $\alpha$ (SK1, Becton Dickinson), CD19 (HIB19, BioLegend), CD56 (HCD56, Biolegend), CD69 (FN50, Becton Dickinson), CD158A/B/F/G/H (mixture of DX27, Biolegend, HP-MA4, eBioscience, and UP-R1, eBioscience), CD161 (191B8, Miltenyi Biotec, or HP-3G10, Biolegend), NKG2D (CD314, 1D11, Biolegend), TRAV10 (C15, Beckman Coulter), TRBV25-1 (C21, Beckman Coulter), TRDV1 (A13; a gift from L. Morretta, Istituto Giannina Gaslini, Italy), isotype controls (mouse IgG2b, MPC-11, Biolegend and mouse IgG1, MOPC-21, Biolegend) and 7-aminoactinomycin D viability dye (Sigma) All antibodies were used at empirically determined dilution factors. Cells were stained with human and mouse CD1d tetramers as previously described ${ }^{22}$ CD1d- $\alpha$-GalCer tetramer ${ }^{+}$cells were enriched using anti-phycoerythrin magnetic beads (Miltenyi Biotec), followed by cell sorting of CD3 ${ }^{+} \mathrm{CD} 1 \mathrm{~d}-\alpha-\mathrm{GalCer}$ tetramer ${ }^{+}$cells using a FACSAria (BD Biosciences). Cells were then expanded for 14-21 days using anti-CD3, anti-CD28, IL-2, IL-7 and phytohemagglutinin as previously described ${ }^{22}$, and were analysed on an LSRFortessa (BD Biosciences). Data analysis was performed using FlowJo (Tree Star Inc).

Lipids. $\mathrm{C}_{24: 1}$ (PBS44) was kindly provided by P. Savage (Brigham Young University). $\alpha$-GalCer $C_{26: 0}$ was supplied by Alexis Biochemicals, and sulfatide $\left(\mathrm{C}_{24: 1}\right), \beta$-GalCer $\left(\mathrm{C}_{12}\right)$ and $\beta$-GlcCer $\left(\mathrm{C}_{24: 1}\right)$ were purchased from Avanti Polar Lipids. Disialo-ganglioside GD3 was purchased from Matreya. $\alpha$-GlcCer $\left(\mathrm{C}_{20: 2}\right)$, $\alpha$-GalCer $\left(\mathrm{C}_{20: 2}\right.$ analogue), and $\mathrm{OCH}$ were produced in house (at the University of Birmingham, UK). $\alpha$-GalCer $\left(\mathrm{C}_{26: 0} 3^{\prime}, 4^{\prime \prime}\right.$-dideoxy- ' 3 '-deoxy- $\alpha$-GalCer' and $\mathrm{C}_{26: 0}$ $4^{\prime}, 4^{\prime \prime}$-dideoxy ' 4 '-deoxy- $\alpha$-GalCer' analogues) were produced in house (at the University of Connecticut $)^{47}$. Lipids were dissolved in $0.5 \% \mathrm{v} / \mathrm{v}$ Tyloxapol (Sigma), or buffer containing $0.5 \% \mathrm{v} / \mathrm{v}$ tween-20, $57 \mathrm{mg} \mathrm{ml}^{-1}$ sucrose and $7.5 \mathrm{mg} \mathrm{ml}^{-1}$ histidine, and loaded into CD1d at a three to sixfold molar excess overnight.

TCR identification. $\mathrm{CD}^{+}{ }^{+} \mathrm{CD} 1 \mathrm{~d}-\alpha-\mathrm{GalCer}$ tetramer ${ }^{+} \gamma \delta \mathrm{TCR}^{-} \mathrm{TRBV}^{-} 5-1^{-}$ cells, or alternatively CD3 ${ }^{+}$CD1d- $\alpha-$ GalCer tetramer ${ }^{+}{\text {TRAV } 10^{-}}^{-}$cells, were single-cell sorted from CD1d- $\alpha$-GalCer tetramer-enriched/expanded NKT cells (see above), and complementary DNA generated using SuperScript VILO (Invitrogen) in accordance with manufacturer's instructions. Transcripts encoding TCR $\alpha$ and TCR $\beta$ chains were amplified as described ${ }^{48}$, with the exception of 9C1 TCR $\alpha$, which was identified by $5^{\prime}$-RACE PCR according to manufacturer's instructions (Invitrogen). Here complementary DNA was generated from bulk-sorted CD1d- $\alpha$-GalCer tetramer ${ }^{+}$TRBV25-1 ${ }^{-}$cells with a gene-specific TRAC primer (5'-GACCAGCTTGACATCACA-3'), followed by amplification with a nested TRAC reverse primer $\left(5^{\prime}\right.$ GGGAAGAAGGTGTCTTCTGGAAT-3'), and subsequent cloning of PCR products into pGEM-T Easy (Promega). PCR fragments were separated using a $1.5 \%$ agarose gel and DNA sequenced by Molecular Diagnostics (the University of Melbourne). TCR sequence analysis was performed using the IMGT online analysis interface, and TCR nomenclature, numbering and CDR3 lengths are presented in accordance with the IMGT system ${ }^{49}$. Unproductively rearranged TCR genes were excluded from analysis.

\section{Generation of cell lines and stimulation assay. TCR constructs containing} full-length TCR $\alpha$ and TCR $\beta$ chains separated by a 2A-cleavable linker were synthesized (Genscript), and cloned into the pMIG2 plasmid. Generation of cell lines was achieved by retroviral transduction of $\alpha \beta$ TCR-deficient Jurkat-76 cells

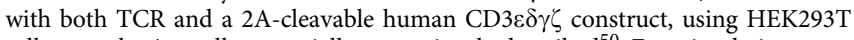
cells as packaging cells, essentially as previously described ${ }^{50}$. For stimulation assays, $3 \times 10^{4}$ TCR-expressing Jurkat-76 or SKW3 cells were co-cultured overnight, with or without $3 \times 10^{4}$ C1R (either C1R WT, C1R.CD1d ${ }^{\text {int }}$ or C1R.CD1d ${ }^{\text {hi }}$ ) cells, with graded concentrations of lipid in round-bottom 96-well plates, and CD19 ${ }^{-}$cells were analysed by flow cytometry for CD69 expression. For stimulation assays using primary NKT cells, PBMCs were enriched for CD1d- $\alpha$-GalCer-tetramer ${ }^{+}$cells using magnetic beads as described above, then $\mathrm{CD}^{+} \gamma \delta \mathrm{TCR}^{-} \mathrm{CD} 1 \mathrm{~d}-\alpha-\mathrm{GalCer}$ tetramer $^{+}$TRBV25-1 $1^{+l-}$ cells were enriched by flow cytometric sorting and cultured for 2 days in the presence of plate-bound anti-CD3 (UCHT1, $\left.10 \mu \mathrm{g} \mathrm{ml}^{-1}\right)$, soluble anti-CD28 (CD28.2, $\left.1 \mu \mathrm{g} \mathrm{ml}^{-1}\right)$, IL-2 $\left(100 \mathrm{U} \mathrm{ml}^{-1}\right)$, IL-7 $\left(50 \mathrm{ng} \mathrm{ml}^{-1}\right)$, PHA $\left(0.5 \mu \mathrm{g} \mathrm{ml}^{-1}\right), 10^{5}$ irradiated allogeneic PBMC and $2 \times 10^{4}$ irradiated CD1d-expressing K562 cells, and subsequently maintained in media containing IL-2 and IL-7. After $\sim 2$ weeks, cultured cells were then re-sorted into type I NKT (CD1d- $\alpha$-GalCer tetramer ${ }^{+}$TRBV25-1 ${ }^{+}$TRDV1 $^{-}$), atypical NKT (CD1d- $\alpha$-GalCer tetramer ${ }^{+}$TRBV25-1 ${ }^{-}$TRDV $^{-}$), $\delta / \alpha \beta$ NKT (CD1d- $\alpha$-GalCer tetramer $\left.{ }^{+} \gamma \delta \mathrm{TCR}^{-} \mathrm{TRDV}^{+}\right)$and control T (CD1d- $\alpha-\mathrm{GalCer}$ tetramer TRBV25-1 ${ }^{-}$TRDV $^{-}$) cell subsets, and purity was confirmed $(>95 \%)$. About $4-5 \times 10^{3}$ cells were cultured with $2 \times 10^{4} \mathrm{CD} 1 \mathrm{~d}$-expressing K562 cells, + / - lipid $\mathrm{Ag}$ (each at $0.5 \mu \mathrm{g} \mathrm{ml}^{-1}$ ), for $24 \mathrm{~h}$ in $50 \mu \mathrm{l}$ media containing no IL-2 or IL-7, and cytokine concentrations were assayed by cytometric bead array(BD Biosciences) according to manufacturer's instructions.

Surface plasmon resonance. SPR experiments were conducted at $25^{\circ} \mathrm{C}$ on a ProteOn XPR36 (Bio-Rad) instrument using HBS-T buffer (10 mM HEPES, pH 7.4, $150 \mathrm{mM} \mathrm{NaCl}$ and $0.005 \%$ surfactant P-20). Biotinylated human CD1d was loaded with $\alpha$-GalCer $\left(\mathrm{C}_{26: 0}\right), \alpha$-GlcCer $\left(\mathrm{C}_{26: 0}\right), 3^{\prime}$-deoxy- $\alpha$-GalCer and $4^{\prime}$-deoxy- $\alpha$-GalCer, and $400-600$ RU was coupled to a GLC sensor chip surface via streptavidin, after which free streptavidin was blocked with an injection of D-biotin. Serial dilutions of purified soluble 9C1 TCR, 9B2 TCR, NKT15 TCR or mutants thereof (starting TCR concentrations between 19.1 and $128 \mu \mathrm{M}$ ) were injected at $25 \mu \mathrm{l}$ per minute for $60 \mathrm{~s}$, simultaneously over test and control (streptavidin alone) flow cells, using HBS-T buffer. Data were referenced against the control flow cell and analysed using ProteOn Manager version 2.1 (Bio-Rad) software, and $K_{\mathrm{D}}, K_{\mathrm{a}}$ and $t_{1 / 2}$ values derived using a 1:1 Langmuir binding model. For TCR mutant analysis, $K_{\mathrm{D}}$ values were normalized against WT TCR $K_{\mathrm{D}}$ values.

Generation of soluble TCRs and CD1d. The individual TCR $\alpha$ and $\beta$ chains of the 9C1 and 9B2 TCRs were synthesized (Integrated DNA Technologies) and cloned into the pET30 vector (Novagen). The $9 \mathrm{C} 1$ and $9 \mathrm{~B} 2$ TCR mutants were produced by overlapping extension PCR with primers that included the desired mutations. The 9C1 and 9B2 wild-type and mutants TCRs were transformed into E. coli BL21 (DE3) pLysS for expression and produced as inclusion bodies. Both TCRs were subsequently produced by oxidative refolding as previously described and purified by size exclusion chromatography, hydrophobic interaction chromatography and anion exchange chromatography ${ }^{5}$. Soluble human CD1d either with or without a $\mathrm{C}$ terminus BirA biotin ligase tag, along with $\beta 2$-microglobulin, or mouse CD1d and $\beta 2$-microglobulin, were cloned into pFastBac Dual (Life Technologies) and expressed by baculovirus infection of High Five insect cell lines as previously described $^{51,52}$. CD1d was purified by immobilized metal affinity chromatography followed by size exclusion chromatography using gel filtration (GE Healthcare).

Structure determination and refinement. The 9C1 TCR-CD1d- $\alpha$-GalCer and 9B2 TCR-CD1d- $\alpha$-GalCer complex crystals were obtained in 9-10\% PEG 6000/0.1 M MES pH 6.0/4\% ethylene glycol and 18\% PEG 8000/0.1 M CHES pH 9.5 , respectively. The $9 \mathrm{C} 1$ and $9 \mathrm{~B} 2$ complex crystals were flash-frozen and data were collected at the MX2 beamline (Australian Synchrotron) to $2.5 \AA$ and $3.1 \AA$ resolution, respectively. Crystals of the $9 \mathrm{C} 1 \mathrm{TCR}$ were obtained in $20 \%$ PEG $3000 / 0.2 \mathrm{M} \mathrm{Na}$ acetate/0.1 M Tris- $\mathrm{HCl}$ pH 7.0 and data were collected at the MX1 beamline (Australian Synchrotron) to $1.4 \AA$ resolution. All the data were processed with the programme MOSFLM and were scaled with the CCP4 suite ${ }^{53}$. The $9 \mathrm{C} 1$ and 9B2 complex crystals belonged to the $\mathrm{C} 2$ and $\mathrm{P} 2{ }_{1} 2_{1} 2_{1}$ space groups, respectively, and the unit cells were consistent with one complex in the asymmetric unit for both complexes. The $9 \mathrm{C} 1 \mathrm{TCR}$ crystal belonged to the $\mathrm{P} 2{ }_{1}$ space group. For the 9C1 TCR, molecular replacement was carried out with the programme PHASER $^{54}$, using the NKT15 TCR (PDB code: 2PO6). For the 9C1-CD1d- $\alpha$ GalCer, a molecular replacement solution was found with the programme PHASER $^{54}$ using the structures of human CD1d without the lipid (pdb code: 2PO6) and the refined 9C1 TCR minus the CDR loops as two separate search ensembles. The 9B2 TCR-CD1d- $\alpha$-GalCer crystal structure was also determined by molecular replacement (PHASER) and using human CD1d without the lipid (PDB code: 2PO6) and the NKT15 TCR minus the CDR loops as two separate search ensembles. For the three crystal structures, an initial run of rigid body refinement was performed with the refinement programme BUSTER 2.10 (ref. 55) and the CDR loops of the TCRs were subsequently rebuilt using the programme COOT ${ }^{56}$ The density of the $\alpha$-GalCer headgroup was unambiguous for both complexes. After iterative model building with COOT and refinement with BUSTER 2.10, the $9 \mathrm{C} 1$ and 9B2 complex structures refinement led to an R/R-free (\%) of 20/24.9 and $19.5 / 25.5$, respectively, while an R/R-free (\%) of 19.6/21.7 was obtained for the $9 \mathrm{C} 1$ TCR structure. The quality of the three structures was confirmed at the Research Collaboratory for Structural Bioinformatics Protein Data Bank Data Validation and Deposition Services website and using the server Molprobity ${ }^{57}$. All presentations of molecular graphics were created with the PyMOL molecular visualization system ${ }^{58}$.

\section{References}

1. Rossjohn, J. et al. T cell antigen receptor recognition of antigen-presenting molecules. Annu. Rev. Immunol. 33, 169-200 (2015).

2. Eckle, S. B. G., Turner, S. J., Rossjohn, J. \& McCluskey, J. Predisposed $\alpha \beta$ T cell antigen receptor recognition of MHC and MHC-I like molecules? Curr. Opin. Immunol. 25, 653-659 (2013). 
3. Godfrey, D. I., Uldrich, A. P., McCluskey, J., Rossjohn, J. \& Moody, D. B. The burgeoning family of unconventional T cells. Nat. Immunol. 16, 1114-1123 (2015).

4. Brigl, M. \& Brenner, M. B. CD1: antigen presentation and T cell function. Annu. Rev. Immunol. 22, 817-890 (2004).

5. Ly, D. \& Moody, D. B. The CD1 size problem: lipid antigens, ligands, and scaffolds. Cell. Mol. Life Sci. 71, 3069-3079 (2014).

6. Godfrey, D. I., MacDonald, H. R., Kronenberg, M., Smyth, M. J. \& Van Kaer, L. NKT cells: what's in a name? Nat. Rev. Immunol. 4, 231-237 (2004).

7. Kawano, T. et al. CD1d-restricted and TCR-mediated activation of valpha14 NKT cells by glycosylceramides. Science 278, 1626-1629 (1997).

8. Rossjohn, J., Pellicci, D. G., Patel, O., Gapin, L. \& Godfrey, D. I. Recognition of CD1d-restricted antigens by natural killer T cells. Nat. Rev. Immunol. 12, 845-857 (2012).

9. Rhost, S., Sedimbi, S., Kadri, N. \& Cardell, S. L. Immunomodulatory type II natural killer T (NKT) lymphocytes in health and disease. Scand. J. Immunol. 76, 246-255 (2012).

10. Mallevaey, T. et al. T cell receptor CDR2 beta and CDR3 beta loops collaborate functionally to shape the iNKT cell repertoire. Immunity 31, 60-71 (2009).

11. Wun, K. S. et al. A molecular basis for the exquisite CD1d-restricted antigen specificity and functional responses of natural killer T cells. Immunity 34, 327-339 (2011)

12. Wun, K. S. et al. Human and mouse type I natural killer T cell antigen receptors exhibit different fine specificities for CD1d-antigen Complex. J. Biol. Chem. 287, 39139-39148 (2012).

13. Stanic, A. K. et al. Another view of T cell antigen recognition: cooperative engagement of glycolipid antigens by Va14Ja18 natural TCR. J. Immunol. 171, 4539-4551 (2003).

14. Schumann, J., Voyle, R. B., Wei, B. Y. \& MacDonald, H. R. Cutting edge: influence of the TCR Vbeta domain on the avidity of CD1d:alphagalactosylceramide binding by invariant Valpha14 NKT cells. J. Immunol. 170, 5815-5819 (2003).

15. Patel, O. et al. V $\beta 2$ natural killer T cell antigen receptor-mediated recognition of CD1d-glycolipid antigen. Proc. Natl Acad. Sci. USA 108, 19007-19012 (2011).

16. Cameron, G. et al. Antigen specificity of type I NKT cells is governed by TCR $\beta$-chain diversity. J. Immunol. 195, 4604-4614 (2015).

17. Brigl, M. et al. Conserved and heterogeneous lipid antigen specificities of CD1d-restricted NKT cell receptors. J. Immunol. 176, 3625-3634 (2006).

18. Gadola, S. D. et al. Structure and binding kinetics of three different human CD1d-alpha-galactosylceramide-specific T cell receptors. J. Exp. Med. 203, 699-710 (2006)

19. Uldrich, A. P. et al. A semi-invariant $\mathrm{V} \alpha 10+\mathrm{T}$ cell antigen receptor defines a population of natural killer $\mathrm{T}$ cells with distinct glycolipid antigen-recognition properties. Nat. Immunol. 12, 616-623 (2011).

20. López-Sagaseta, J., Kung, J. E., Savage, P. B., Gumperz, J. \& Adams, E. J. The molecular basis for recognition of CD1d/ $\alpha$-galactosylceramide by a human non-V 224 T cell receptor. PLoS Biol. 10, e1001412 (2012).

21. Constantinides, M. G., Picard, D., Savage, A. K. \& Bendelac, A. A naive-like population of human CD1d-restricted T Cells expressing intermediate levels of promyelocytic leukemia zinc finger. J. Immunol. 187, 309-315 (2011).

22. Uldrich, A. P. et al. CD1d-lipid antigen recognition by the $\gamma \delta$ TCR. Nat. Immunol. 14, 1137-1145 (2013).

23. Borg, N. A. et al. CD1d-lipid-antigen recognition by the semi-invariant NKT T-cell receptor. Nature 448, 44-49 (2007).

24. Mallevaey, T. et al. A molecular basis for NKT cell recognition of CD1d-self-antigen. Immunity 34, 315-326 (2011).

25. Pellicci, D. G. et al. Recognition of $\beta$-linked self glycolipids mediated by natural killer T cell antigen receptors. Nat. Immunol. 12, 827-833 (2011).

26. Wun, K. S. et al. A minimal binding footprint on CD1d-glycolipid is a basis for selection of the unique human NKT TCR. J. Exp. Med. 205, 939-949 (2008).

27. Pellicci, D. G. et al. Differential recognition of CD1d-alpha-galactosyl ceramide by the $\mathrm{V}$ beta 8.2 and $\mathrm{V}$ beta 7 semi-invariant NKT $\mathrm{T}$ cell receptors. Immunity 31, 47-59 (2009).

28. Florence, W. C. et al. Adaptability of the semi-invariant natural killer T-cell receptor towards structurally diverse CD1d-restricted ligands. EMBO J. 28, 3579-3590 (2009).

29. Li, Y. et al. The V $\alpha 14$ invariant natural killer T cell TCR forces microbial glycolipids and CD1d into a conserved binding mode. J. Exp. Med. 207, 2383-2393 (2010)

30. Aspeslagh, S. et al. Galactose-modified iNKT cell agonists stabilized by an induced fit of CD1d prevent tumour metastasis. EMBO J. 30, 2294-2305 (2011).

31. Yu, E. D., Girardi, E., Wang, J. \& Zajonc, D. M. Cutting edge: structural basis for the recognition $\beta$-linked glycolipid antigens by invariant NKT cells. J. Immunol. 187, 2079-2083 (2011).

32. Kinjo, Y. et al. Invariant natural killer $\mathrm{T}$ cells recognize glycolipids from pathogenic Gram-positive bacteria. Nat. Immunol. 12, 966-974 (2011).
33. Lopez-Sagaseta, J., Sibener, L. V., Kung, J. E., Gumperz, J. \& Adams, E. J. Lysophospholipid presentation by CD1d and recognition by a human natural killer T-cell receptor. EMBO J. 31, 2047-2059 (2012).

34. Girardi, E. et al. Unique interplay between sugar and lipid in determining the antigenic potency of bacterial antigens for NKT cells. PLoS Biol. 9, e1001189 (2011).

35. Matulis, G. et al. Innate-like control of human iNKT cell autoreactivity via the hypervariable CDR3beta loop. PLoS Biol. 8, el000402 (2010).

36. Patel, O. et al. Recognition of CD1d-sulfatide mediated by a type II natural killer T cell antigen receptor. Nat. Immunol. 13, 857-863 (2012).

37. Girardi, E. et al. Type II natural killer T cells use features of both innate-like and conventional T cells to recognize sulfatide self antigens. Nat. Immunol. 13, 851-856 (2012).

38. Gadola, S. D., Dulphy, N., Salio, M. \& Cerundolo, V. V alpha 24-J alpha Q-independent, CD1d-restricted recognition of alpha-galactosylceramide by human CD4 $(+)$ and CD8 alpha beta $(+)$ T lymphocytes. J. Immunol. 168, 5514-5520 (2002).

39. Brennan, P. J. et al. Activation of iNKT cells by a distinct constituent of the endogenous glucosylceramide fraction. Proc. Natl Acad. Sci. USA 111, 13433-13438 (2014).

40. Pellicci, D. G. et al. The molecular bases of $\delta / \alpha \beta$ T cell-mediated antigen recognition. J. Exp. Med. 211, 2599-2615 (2014).

41. Scott-Browne, J. P. et al. Germline-encoded recognition of diverse glycolipids by natural killer T cells. Nat. Immunol. 8, 1105-1113 (2007).

42. Girardi, E. \& Zajonc, D. M. Molecular basis of lipid antigen presentation by CD1d and recognition by natural killer T cells. Immunol. Rev. 250, 167-179 (2012).

43. Cui, J. Q. et al. Requirement for V(Alpha)14 Nkt cells in Il-12-mediated rejection of tumors. Science 278, 1623-1626 (1997).

44. Luoma, A. M. et al. Crystal structure of V $\delta 1 \mathrm{~T}$ cell receptor in complex with CD1d-sulfatide shows MHC-like recognition of a self-lipid by human gammadelta T cells. Immunity 39, 1032-1042 (2013).

45. Cerundolo, V., Barral, P. \& Batista, F. D. Synthetic iNKT cell-agonists as vaccine adjuvants $\dagger--\dagger$ finding the balance. Curr. Opin. Immunol. 22, 417-424 (2010).

46. Venkataswamy, M. M. \& Porcelli, S. A. Lipid and glycolipid antigens of CD1d-restricted natural killer T cells. Semin. Immunol. 22, 68-78 (2010).

47. Raju, R. et al. Synthesis and evaluation of $3^{\prime \prime}$ - and $4^{\prime \prime}$-deoxy and -fluoro analogs of the immunostimulatory glycolipid, KRN7000. Bioorg. Med. Chem. Lett. 19, 4122-4125 (2009).

48. Wang, G. C., Dash, P., McCullers, J. A., Doherty, P. C. \& Thomas, P. G. T cell receptor $\alpha \beta$ diversity inversely correlates with pathogen-specific antibody levels in human cytomegalovirus infection. Sci. Transl. Med. 4, 128ra142 (2012).

49. Lefranc, M.-P. et al. IMGT, the international ImMunoGeneTics information system(R). Nucleic Acids Res. 33, D593-D597 (2005).

50. Holst, J., Vignali, K. M., Burton, A. R. \& Vignali, D. A. A. Rapid analysis of T-cell selection in vivo using T cell-receptor retrogenic mice. Nat. Methods 3, 191-197 (2006).

51. Kjer-Nielsen, L. et al. A structural basis for selection and cross-species reactivity of the semi-invariant NKT cell receptor in CD1d/glycolipid recognition. J. Exp. Med. 203, 661-673 (2006)

52. Matsuda, J. L. et al. Tracking the response of natural killer T cells to a glycolipid antigen using CD1d tetramers. J. Exp. Med. 192, 741-754 (2000).

53. Winn, M. D. et al. Overview of the CCP4 suite and current developments. Acto Crystallogr. D Biol. Crystallogr. 67, 235-242 (2011).

54. McCoy, A. J. Solving structures of protein complexes by molecular replacement with Phaser. Acta Crystallogr. D Biol. Crystallogr. 63, 32-41 (2007).

55. Bricogne, G. et al. autoBUSTER, Version 1.6.0. (Global Phasing, Cambridge, UK, 2011).

56. Emsley, P., Lohkamp, B., Scott, W. G. \& Cowtan, K. Features and development of Coot. Acta Crystallogr. D Biol. Crystallogr. 66, 486-501 (2010).

57. Chen, V. B. et al. MolProbity: all-atom structure validation for macromolecular crystallography. Acta Crystallogr. D Biol. Crystallogr. 66, 12-21 (2010).

58. DeLano, W. L. Unraveling hot spots in binding interfaces: progress and challenges. Curr. Opin. Struct. Biol. 12, 14-20 (2002).

\section{Acknowledgements}

We thank staff at the Australian synchrotron, the Monash macromolecular crystallization facility, Shin Yi Tin, John Waddington, Marcin Ciula and Ben O'Sullivan for technical assistance. We also thank Professors Paul Savage for providing $\alpha$-GalCer (PBS44) and Lorenzo Moretta for providing anti-TRDV1 mAb. This work was supported by the National Health and Medical Research Council of Australia (NHMRC \#1013667 and \#1083885), The Cancer Council of Victoria the Australian Research Council (ARC) (CE140100011, LP140100920 and LE110100106) and the NIH RO1 GM087136 (to A.R.H.). D.G.P. is supported by an NHMRC ECF fellowship (\#1054431); D.I.G. is supported by an NHMRC Senior Principal Research Fellowship (\#1020770); J.R. is supported by an NHMRC Australia Fellowship (AF50); A.P.U. and S.G. are supported by an ARC Future Fellowships (FT140100278 and FT120100416). 


\section{Author contributions}

J.L.N. and T.P. produced the 9B2 TCR and CD1d protein complexes, and performed crystallography studies. D.G.P. performed tetramer and Ag-reactivity assays and produced the 9C1 TCR protein complex for crystallographic studies. N.A.G., F.J.R. and R.T.L. performed phenotypic and CD1d-Ag flow cytometry assays. G.B., S.K., S.K.R. and A.R.H. provided reagents crucial to this study. S.G. collected and processed data at the Australian Synchrotron. A.P.U. identified the atypical NKT cells, performed TCR sequencing and SPR assays, and generated TCR transduced cell lines. D.I.G., J.R. and A.P.U. co-led the investigation, devised the project and wrote the paper.

\section{Additional information}

Supplementary Information accompanies this paper at http://www.nature.com/ naturecommunications
Competing financial interests: The authors declare no competing financial interests.

Reprints and permission information is available online at http://npg.nature.com/ reprintsandpermissions/

How to cite this article: Le Nours, J. et al. Atypical natural killer T-cell receptor recognition of CD1d-lipid antigens. Nat. Commun. 7:10570 doi: 10.1038/ncomms10570 (2016).

(c) (i)

This work is licensed under a Creative Commons Attribution 4.0 International License. The images or other third party material in this article are included in the article's Creative Commons license, unless indicated otherwise in the credit line; if the material is not included under the Creative Commons license, users will need to obtain permission from the license holder to reproduce the material. To view a copy of this license, visit http:// creativecommons.org/licenses/by/4.0/ 